\title{
Article
}

\section{From highly graphitic to amorphous carbon dots: a critical review}

\author{
Kelarakis, Antonios \\ Available at http://clok.uclan.ac.uk/12861/ \\ Kelarakis, Antonios ORCID: 0000-0002-8112-5176 (2014) From highly \\ graphitic to amorphous carbon dots: a critical review. MRS Energy and \\ Sustainability, 1 (2). ISSN 2329-2229
}

It is advisable to refer to the publisher's version if you intend to cite from the work. http://dx.doi.org/10.1557/mre.2014.7

For more information about UCLan's research in this area go to

http://www.uclan.ac.uk/researchgroups/ and search for <name of research Group>.

For information about Research generally at UCLan please go to http://www.uclan.ac.uk/research/

All outputs in CLoK are protected by Intellectual Property Rights law, including Copyright law. Copyright, IPR and Moral Rights for the works on this site are retained by the individual authors and/or other copyright owners. Terms and conditions for use of this material are defined in the policies page.

\section{CLoK}

Central Lancashire online Knowledge www.clok.uclan.ac.uk

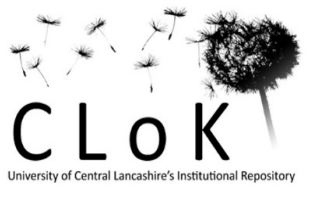


Article

Title

Creators

CLOK URL

Date

Citation

Official URL

Copyright

\section{Functional nanomaterials for energy and sustainability}

\author{
Kelarakis, Antonios
}

http://clok.uclan.ac.uk/11461/

2014

Kelarakis, Antonios (2014) Functional nanomaterials for energy and sustainability. Advanced Materials IETTERS, 5 (5). pp. 236-241.

\#\#rights\#\#

"For more information about UCLan's research in this area go to www.uclan.ac.uk/researchgroups and search for <name of research Group>."

UCLan has developed Central Lancashire online Knowledge (CLoK) so that users may access the research outputs of the university. Copyright $(\subset$ and Moral Rights for the papers on this site are retained by the individual authors and/or other copyright owners. Users may download and/or print one copy of any article(s) in CLoK to facilitate their private study or for non-commercial research. You may not engage in further distribution of the material or use it for any profit-making activities or any commercial gain. You may freely distribute the URL (http://clok.uclan.ac.uk) of the CLoK website.

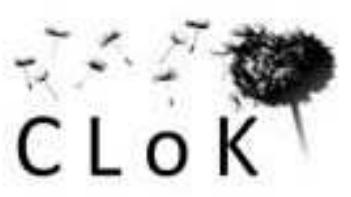




\title{
From highly graphitic to amorphous carbon dots: a critical review
}

\author{
Antonios Kelarakis
}

Centre for Materials Science, School of Forensic and Investigative Sciences,

University of Central Lancashire, Preston PR12HE, U.K.

Tel.01772894172, email:akelarakis@uclan.ac.uk

\begin{abstract}
The emergence of carbogenic nanoparticles (C-dots) as a new class of photoluminescent (PL) nanoemitters is directly related to their economical preparation, non-toxic nature, versatility and tuneability. C-dots are typically prepared by pyrolytic or oxidative treatment of suitable precursors. While the surface functionalities critically affect the dispesrsibility and the emission intensity of C-dots in a given environment, it is the nature of the carbogenic core that actually imparts their intrinsic PL properties. Depending on the synthetic approach and the starting materials, the structure of the carbogenic core can vary from highly graphitic all the way to completely amorphous. This critical review focuses on correlating the functions of C-dots with the graphitic or amorphous nature of their carbogenic cores. The systematic classification on that basis can provide insights on the origins of their intriguing photophysical behaviour and can contribute in realising their full potential in challenging applications.
\end{abstract}

Email: akelarakis@uclan.ac.uk

Keywords: luminescence, nanostructure, carbonization 


\section{Introduction}

The emergence of carbogenic nanoparticles (otherwise known as C-dots) as a new class of photoluminescent (PL) nanoemitters has led to worth mentioning paradoxes about the fascinating story of molecular carbons. First, it is the realisation that those nanoparticles are abundant in the planet (in the form of tiny graphitic fragments or combustion products), but they have gone unnoticed until recently. Chronologically, the first observation of C-dots ${ }^{1}$ falls close to the isolation of graphene by mechanical exfoliation ${ }^{2}$, but those ground-breaking advances only took place few years after the development of fullerenes ${ }^{3}$ and carbon nanotubes $^{4}(\mathrm{CNTs})$.

Second, it is the realistic perspective that those, oftentimes naturally or incidentally occurring nanoparticles (Figure 1), can adequately replace highly engineered semiconductor emitters (commonly referred as heavy metal based quantum dots) in demanding applications where extensive optical absorption, excitation wavelength dependent emission, multi phonon excitation and upconversion are needed. While ultra-long, defect-free graphene sheets are ideal for electronics, the exact opposite features e.g. surface defects and fragmentation seem to be a precondition for PL.

Third, systematic efforts are currently directed to the development of well-defined C-dots, at a time where a rigorous definition of $\mathrm{C}$-dots is notably absent in the literature. The problem relates to their great compositional diversity in terms of elemental content and graphitization degree. That being said, it is surprising that structurally very dissimilar C-dots share common patterns in their behaviour (such as excitation dependent emission and upconversion).

By virtue of their PL properties, C-dots are extensively explored in a broad range of technological applications including multicolour printing, bioimaging, optical sensors, photocatalysis and solar cells $\mathrm{s}^{5-11}$. Compared to organic dyes and heavy metals based quantum 
dots, they show minimal toxicity for humans and environment, low preparation cost, enhanced solubility in a variety of solvents and improved chemical and colloidal stability.

The rapidly expanding body of experimental work centred on C-dots has been summarized in extensive reviews $^{5-11}$. In those studies it appears that the terms C-dots, carbon quantum dots, carbon nanoparticles, carbogenic nanoparticles, quantum sized carbon dots, graphene quantum dots are used rather loosely in the literature. Within this somewhat confusing framework, this review describes the properties of C-dots with respect to the structure of their cores that vary from highly graphitic all the way to completely amorphous. It should be noted that certain synthetic approaches tend to generate a mixture of carbogenic cores with inhomogeneous graphitization degree. A systematic classification on that basis can promote our understanding on their photoactive behaviour and can contribute in further advancing their performance.

\section{Discussion}

\subsection{Synthesis and structure}

\subsubsection{Highly graphitic C-dots (gC-dots)}

Disks of single-layer graphene (refereed hereafter as Graphene Quantum dots or GQ-dots) are considered for the purposes of this review as a subgroup of the highly graphitic C-dots (gCdots). Their technological importance stems from their supreme electronic conductivity and structural stability, even if graphene is broken down to the level of a few aromatic groups ${ }^{12}$. GQ-dots are produced via hydrothermal etching of $\mathrm{CNTs}^{13}$, high resolution electron beam lithography ${ }^{12}$ or oxygen plasma treatment of graphene ${ }^{14}$. The cage opening of fullerenes is a rather unique process where the $\mathrm{C}_{60}-\mathrm{Ru}$ attractive forces induce surface vacancies in the $\mathrm{Ru}$ 
crystal to accommodate $\mathrm{C}_{60}$ particles. At elevated temperatures the embedded molecules undergo diffusion and aggregation to form GQ-dots ${ }^{15}$ (Figure 2a).

All-organic, chemical approaches allow the synthesis of large, yet colloidal stable GQ-dots with excellent uniformity and tuneable dimensions ${ }^{16,17}$. The synthetic strategy relies on the oxidation of polyethylene dendritic precursors to create graphene moieties that are further stabilised against self-aggregation by attaching bulky 2,4,6-trialkyl phenyl groups to their edges $^{16,17}$ (Figure 2b).

Solvothermal approaches, such as the high pressure hydrothermal fragmentation of sucrose, afford the ring opening of the hydrolysed compounds, formation of dehydrated furfural compounds, followed by hydronium-catalysed polymerization and carbonization towards $\mathrm{gC}$ $\operatorname{dots}^{18}$.

Alternatively, gC-dots were produced via laser ablation of graphite powders followed by $\mathrm{HNO}_{3}$ oxidation, but the resultant nanoparticles became photoactive only after surface passivation with amine terminated oligomers or polymers ${ }^{19}$. gC-dots consisting of 1-3 layers are derived by chemical oxidation and cutting of micrometer-sized carbon fibres ${ }^{20}$, exfoliation and disintegration of graphitic flakes and CMTs ${ }^{21}$ and hydrothermal breakdown of pre-oxidised graphite sheets ${ }^{22}$. A proposed mechanism for the chemical splitting of graphitic materials towards $\mathrm{gC}$-dots is depicted in Figure $3 \mathrm{a}$.

Another well-explored strategy relies on the electrochemical oxidation of $\mathrm{CNTs}^{23}$ or graphite $^{24-26}$ that serve as the working electrodes in typical electrochemical cells (Figure 3b). Suitable electrolytes include ultrapure water $^{27}$, phosphate buffer solutions ${ }^{24}$, $\mathrm{NaOH} /$ ethanol $^{26,27}$, ionic liquid-water mixtures ${ }^{28}$ and acetonitrile ${ }^{23}$. Upon application of a scanning potential, extensive electrode exfoliation facilitates the release of gC-dots. Mechanistically, the electrooxidation has been related to the formation of hydroxyl and 
oxygen radicals (produced by the electrolysis of the solvent) that attack the graphitic anode on defect and edge sites. This process allows the electrolyte to intercalate the graphitic layers, leading to electrode chipping and the formation of $\mathrm{gC}-\mathrm{dots}^{28}$.

Based on this approach green luminescent $\mathrm{gC}$-dots were prepared using a graphene film as the working electrode, $\mathrm{Pt}$ wire as the counter electrode, $\mathrm{Ag} / \mathrm{AgCl}$ as the reference electrode and a phosphate buffer solution with $\mathrm{pH} 6.7$ as the electrolyte (cycling voltammetry window $\pm 3 \mathrm{~V})^{29}$. Transmission Electron Microscopy (TEM) images suggest a narrow size distribution of $\mathrm{gC}$-dots with diameters in the range 3-5 nm (Figure $4 \mathrm{a}, \mathrm{b}, \mathrm{c}$ ), while their Atomic Force Microscopy (AFM) topographic heights are lower than $2 \mathrm{~nm}$ consistent with the stacking of 1-3 graphene layers (Figure 4 d,e). The X-ray Diffraction (XRD) pattern of gC-dots (Figure 4 f) displays a broad peak at $3.4 \AA$ compared to $3.7 \AA$ for the parental graphene electrode. The Raman spectrum of gC-dots (Figure $4 \mathrm{~g}$ ) is dominated by two peaks centred at 1365 and 1596 $\mathrm{cm}^{-1}$ that correspond to the $\mathrm{D}$ and $\mathrm{G}$ bands of the graphitic and amorphous carbon, respectively. The $\mathrm{G}$ peak is associated with the $\mathrm{E}_{2 \mathrm{~g}}$ vibration mode of the $\mathrm{sp}^{2}$ bonded carbon and the $\mathrm{D}$ peak is assigned to the $\mathrm{A}_{1 \mathrm{~g}}$ (zone-edge) breathing vibration phonon that becomes active only in close proximity to a $\mathrm{sp}^{3}$ defect $^{30}$. In a first approximation, the intensity ratio of the $\mathrm{D}$ over $\mathrm{G}$ band is an index of the carbon disorder; the value $\mathrm{I}_{\mathrm{D}} / \mathrm{I}_{\mathrm{G}}=0.5$ found here implies a high graphitization degree for the gC-dots. X-ray Photoelectron Spectroscopy (XPS) patterns of $\mathrm{gC}$-dots are compared with the initial graphene electrode in Figure 4h. Both spectra show the $\mathrm{C} 1 \mathrm{~s}$ peak at $284.8 \mathrm{eV}$ and the $\mathrm{O} 1 \mathrm{~s}$ peak at $532 \mathrm{eV}$, however the oxygen content is higher in $\mathrm{gC}$-dots as a direct consequence of the electrooxidation. The deconvolution of $\mathrm{C} 1 \mathrm{~s}$ peak of gC-dots (Figure 4i) reveals the presence of $\mathrm{C}=\mathrm{C}(284.8 \mathrm{eV}), \mathrm{C}-\mathrm{O}(286.8 \mathrm{eV}), \mathrm{C}=\mathrm{O}(287.8$ $\mathrm{eV}$ ) and $\mathrm{COOH}(289 \mathrm{eV})$ bonds, due to hydroxyl, carbonyl and carboxylic acid groups, respectively. Those surface functionalities account for the remarkable colloidal stability of gC-dots. 
In another approach ${ }^{25}$, alkali assisted electrochemical synthesis of $\mathrm{gC}$-dots was achieved using graphite rods as both anode and cathode and a mixture $\mathrm{NaOH} /$ ethanol as the electrolyte. TEM images suggest that the diameters of the resultant nanoparticles fall within the range 1.2-3.8 $\mathrm{nm}$ (Figure 5a). Because the sample is a mixture of nanoparticles emitting at different wavelengths, it shows various emission colours under a fluorescent microscope (Figure 5b). High Resolution TEM (HRTEM) images of gC-dots with different diameters (Figure $5 \mathrm{c}-\mathrm{h}$ ) show that they all have lattice spacing close to $0.32 \mathrm{~nm}$, consistent with the (002) facet of graphite. The Raman spectrum (Figure 5i) indicates an exceptionally low value for the ratio $\mathrm{I}_{\mathrm{D}} / \mathrm{I}_{\mathrm{G}}$, further confirming their highly graphitic structure.

\subsubsection{Amorphous C-dots (aC-dots)}

Amorphous C-dots (aC-dots) can be derived by cracking of a non-graphitic carbon source following, for example, the ultrasonic treatment of a peroxidised suspension of active carbon $^{31}$, but the most popular approaches rely on the pyrolytic treatment of carbon-rich molecular precursors. Those strategies are usually described as "bottom-up", however there is growing evidence to suggest that they tend to generate large carbon clusters that are filtered out or broken down to the nanoscale via ultrasonication, oxidation, etc.

Within this general synthetic scheme, carbohydrates ${ }^{32,33}$, grass ${ }^{34}$, gelatine ${ }^{35}$, orange juice ${ }^{36}$, soy milk $^{37}$, strawberry juice ${ }^{38}$, bovine albumin $^{39}$, polyacrylamide ${ }^{40}$ are hydrothermally converted to aC-dots. Similarly, hollow ${ }^{41}$ and silica supported ${ }^{42}$ aC-dots are prepared by hydrothermal carbonization protocols, while aC-dots are derived by direct pyrolysis of coffee grounds ${ }^{43}$ or grass ${ }^{44}$, plasma induced pyrolysis of eggs ${ }^{45}$, barbeque char ${ }^{46}$ and the plant soot ${ }^{47}$.

Luminescent aC-dots with average particle size $3.5-5.5 \mathrm{~nm}$ were realized by microwave mediated caramelization of polyethylene glycol (PEG) in the presence of water ${ }^{48}$. HRTEM 
imaging of the aC-dots do not reveal any discernible lattice fringes and the XRD pattern shows a broad peak at $4.1 \AA$, consistent with highly disordered carbon.

In another report, hydrophilic and organophilic aC-dots were synthesized by thermal treatment of diethylene glycolammonium citrate and octadecylammonium citrate, respectively ${ }^{49}$. The TEM images of the organophilic aC-dots (Figure 6a) display geometrically uniform nanoparticles with average diameter $7 \mathrm{~nm}$ (Figure 6b). The XRD pattern shows two reflection peaks; one centered at $4.3 \AA$ attributed to highly disorder carbon and a sharp one at $4.14 \AA$ consistent with the inter-chain distance of densely packed alkyl chains (Figure 6c).

\subsubsection{In situ formation of functional groups}

Oftentimes, the Achilles's heel of the as prepared C-dots is their relatively weak PL emission, but this behaviour is generally improved by surface passivation. Common surface treatments include reflux with $\mathrm{HNO}_{3} / \mathrm{H}_{2} \mathrm{SO}_{4}$ to generate polar groups ${ }^{50}$, reduction via sodium borohydrate $^{51}$, functionalization with PEG based amines ${ }^{19}$ or small molecules ${ }^{52}$, and coating with $\mathrm{ZnO}$ and $\mathrm{ZnS}^{53}$.

Apart from those post-synthesis surface treatments, controlled carbonization approaches allow the formation of surface functionalities in situ with the synthesis of C-dots. To that end, the presence of an external corona seen in the inset in Figure 6a points to the self- passivation of aC-dots pyrolytically derived by octadecylammonium citrate ${ }^{49}$. The IR spectrum of the aCdots (Figure 6d) reveals characteristic absorption peaks due to the octadecyl chains tethered to the surface along with a strong peak at $1700 \mathrm{~cm}^{-1}$ suggestive of amide linkages ${ }^{49}$. 
Similarly, water dispersible C-dots were prepared by controlled pyrolysis of dopamine ${ }^{54}$, lauryl gallate ${ }^{55}$, polyethylenimine $e^{56}$ or a mixture of ethanolamine and citric acid ${ }^{57,58}$. In a remarkably time-efficient modification of the method, microwave assisted thermal treatment of an aqueous solution containing $\mathrm{PEG}^{48}$ or a mixture of PEG and a saccharide ${ }^{59}$ leads rapidly to self-passivated colloidal aC-dots. Ultrasmall aC-dots with quantum yield up to $47 \%$ have been derived by 1 min pyrolysis of anhydrous citric acid in $\mathrm{N}$-( $\beta$-aminoethyl)- $\gamma$-aminopropyl methyldimethoxy silane ${ }^{60}$. At the same time, sulphuric acid dehydration of the single molecule precursor g-butyrolactone gives rise to $\mathrm{gC}$-dots ${ }^{61}$, while laser irradiation of suspended graphite powder in PEG, or amines also leads self-passivated luminescent C-dots with diamond-like structure ${ }^{62}$.

Chemical groups generated in situ during the synthesis of C-dots can impart additional functionalities. For example, the $\mathrm{gC}$-dots derived by hydrothermal treatment of dopamine ${ }^{54}$ bear distinctive catechol groups on their surface, offering a sensing platform for the detection of Fe (III) ions and dopamine. In another approach, the thermal treatment of a mixture of citric acid and ethanolamine results in the evolution of a series of photoactive materials ${ }^{57}$. At the initial steps of pyrolysis a crosslinked, highly viscous polymer network is formed due to intermolecular condensation and the subsequent formation of a precursor material that exhibits strong excitation independent PL due to the presence of amide containing fluorophores (blue groups in Figure 7). Annealing at higher temperatures gives rise to aCdots that shows dual PL emission; an excitation independent mode stemming from the amide fluorophores and an excitation dependent mode directly related to the evolution of carbogenic core (black spheres in Figure 7). Because the carbogenic core is formed at the expense of the organic fluorophores, the amide driven mode diminishes as the pyrolysis proceeds (Figure 7). The PL emission of the aC-dots is quenched in the presence of $3 \mathrm{~d}$ metal ions $\mathrm{Cr}(\mathrm{III})$ and $\mathrm{Co}(\mathrm{II})$ due to a selective metal- fluorophore complexation. 


\subsubsection{Heteroatoms and functional groups}

Besides carbon and oxygen, several heteroatoms can be introduced to C-dots, altering the charge distribution and the electron donating properties of the carbon atoms. To that end, Nrich C-dots are prepared by post-synthesis doping via $\mathrm{NH}_{3}$, hydrazine or $\mathrm{N}_{2}$ treatments. Alternatively, the heteroatoms are incorporated to the nanoparticles directly from the starting materials; N-doped aC-dots are derived from soy milk ${ }^{37}$ and plant $\operatorname{soot}^{47}$. The $\mathrm{N}$ - doped gCdots derived electrolytically from graphite using tetrabutylammonium perchlorate in acetonitrile as electrolyte ${ }^{63}$ exhibit significant electrocatalytic activity against the oxygen reduction reaction (ORR). The PL signal of $\mathrm{gC}$-dots with $7 \% \mathrm{~N}$ content derived hydrothermally by strawberry juice ${ }^{38}$ is quenched in the presence of $\mathrm{Hg}$ (II).

Nitrogen and sulphur co-doped C-dots (N,S-C-dots) (with total heteroatom content up to 10 $\%)$ are realised via sulphuric acid carbonization of hair fibres ${ }^{64}$ and hydrothermal treatment of a mixture of citric acid and L- cysteine produce ${ }^{65}$ (C-dots exhibit an intriguing excitation independent emission), or citric acid and thiourea ${ }^{66}$. Controlled carbonization of a mixture of citric acid, ethylenediamine and $\mathrm{Mg}(\mathrm{OH})_{2}$ leads to $\mathrm{Mg}$, N- co-doped C-dots with improved PL intensity suitable for in vivo cell imaging ${ }^{67}$. Iron oxide doped aC-dots ${ }^{68}$ and gadolinium doped aC-dots $^{69}$ (via pyrolysis of tris(hydroxymethyl)aminomethane, betaine hydrochloride and gadopentetic acid) show great potential for multimodal Magnetic Resonance Imaging (MRI) parallel to fluorescent monitoring. Boron/nitrogen co-doped C-dots (via hydrothermal treatment of $\mathrm{N}$-(4-hydroxyphenyl)glycine and boric acid) exhibit a reversible "switching on and off" PL mechanism in response to the presence of protoporphyrin and carcinogenic dyes $^{70}$.

\subsection{Properties}

\subsubsection{Photoluminescence behaviour}


An ideally $\pi$ - conjugated monolayer of pristine graphene has zero electronic bandgap and is not photoactive. However, finite sized GQ-dots and nanosized graphitic fragments exhibit characteristic PL properties. It is exactly this intriguing behaviour that actually allowed the first detection of C-dots as the fast moving fluorescent front during electrophoretic purification of arc-discharged soot containing single walled carbon nanotubes ${ }^{1}$. In principle, the PL behaviour of C-dots has been attributed to quantum confinement effects and surface defects.

In semiconductors quantum confinement occurs when the crystal size approaches the exciton Bohr radius and implies an inverse relationship between the bandgap and the crystal size. Theoretical studies in GQ-dots suggest that the energy gap between the highest occupied molecular orbital (HUMO) and the lowest unoccupied molecular orbital (LUMO) decreases with the number of fused aromatic rings from $7 \mathrm{eV}$ for a single benzene ring to $2 \mathrm{eV}$ for $20 \pi$ conjugated aromatic rings ${ }^{71}$.

A series of different sized $\mathrm{gC}$-dots were synthesized by alkali assisted electrooxidation of graphite $^{25}$ and the optical images in water (under white and UV light) are shown in Figure 8a. Their corresponding PL spectra, plotted in Figure 8 b, critically depend upon the size of the gC-dots (Figure 8c).Theoretical calculations on the size dependence of the HUMO-LUMO energy gap (Figure 8d), indicate that nanoparticles with diameter 1.4-2.2 $\mathrm{nm}$ have gap energy in the visible region, in agreement with the experimental observations. Hydrogen plasma treatment (to eliminate the surface oxygen) leaves their PL spectra intact, thus confirming the prominent role of the quantum confinement to the photophysical properties in highly graphitic nanoparticles. 
At the same time, several aspects of the PL behaviour in C-dots cannot be explained in terms of quantum confinement alone. Specifically, the PL spectra of a graphite oxide (GO) thin film can be deconvoluted into two Gaussian bands ( $\mathrm{I}_{\mathrm{p} 1}$ and $\mathrm{I}_{\mathrm{p} 2}$ in Figure 9 a,b,c), indicating the parallel action of two distinct photophysical contributions ${ }^{72}$. Gradual chemical reduction of GO sheets preferentially favours the removal of oxygen atoms positioned far from a $\pi$ conjugated domain. This results in the formation of small and isolated $\mathrm{sp}^{2}$ islands, rather than the expansion of the pre-existing $\mathrm{sp}^{2}$ clusters (Figure $9 \mathrm{~d}$ ). During the stepwise chemical reduction towards a graphene film, the relative intensity of $\mathrm{I}_{\mathrm{p} 2}$ systematically increases with time and is, therefore, attributed to the intrinsic PL of graphene fragments. Moreover, $\mathrm{I}_{\mathrm{p} 2}$ shifts to lower wavelengths, consistent with quantum confinement effects originating from the non-percolated small $\mathrm{sp}^{2}$ domains. At the same time, $\mathrm{I}_{\mathrm{p} 1}$ monotonously decreases with reduction time due to the gradual elimination of the surface defects.

It has been proposed that photogenerated electron and holes pairs are induced within surface traps in C-dots and are stabilized by the passivation agents ${ }^{73}$. This approach is in tandem with the observation that PL intensity in C-dots is oftentimes responsive to external stimuli ${ }^{55,56}$. It has been supported that defects in graphene sheets involving $\mathrm{sp}^{3}$ carbons are structurally no different from carbon atoms placed on the surface of carbogenic nanoparticles and this similarity accounts for the fact that very different types of C-dots share common patterns to their PL behaviour ${ }^{73}$.

In principle, both aC-dots and $\mathrm{gC}$-dots (as well as their heteroatoms doped counterparts) exhibit excitation wavelength dependent emission (Figure 10); as the excitation wavelength increases, the emission peak is displaced to longer wavelengths and a weaker signal is recorded. Upconversion occurs when the emitted radiation have higher energy compared to the incident photons and has also been observed for both $\mathrm{gC}-\mathrm{dots}^{25}$ and aC-dots ${ }^{74}$ (Figure 11). 
The effect is explained in terms of sequential absorption of two or more photons and the formation of metastable, long lived intermediate states ${ }^{75}$. Upconversion is a non-linear optical phenomenon that holds great promise for diagnostics, photodynamic therapy and energy harvest.

\subsubsection{Non-toxic character}

By virtue of their PL nature, the cell uptake and biodistribution of C-dots can be easily monitored. C-dots exhibit excellent photochemical stability and multi photon excitation, enabling deeper in vivo imaging with minimal tissue damage ${ }^{76,77}$. In particular, gC-dots undergo two-photon absorption with the pulsed laser in the near infrared to cause emission in the visible and the absorption cross-section are comparable to the best performing nanoemmitters reported in the literature ${ }^{76}$.

Experimental evidence suggests that $\mathrm{gC}$-dots and $\mathrm{aC}$-dots are preferentially localised in the cytoplasm rather than the cell nucleus ${ }^{76-79}$ (Figure 12). Intravenously injected gC-dots (derived from laser ablation and passivated with $\mathrm{ZnS}$ and PEG diamine) in mice for whole body circulation follow the urine excretion pathway, after being temporarily accumulated to kidneys. Following interdermal injection into the front extremity, the $\mathrm{gC}$ - dots were seen to migrate along the arm to the axillary lymph node, albeit in a somewhat slower speed compared to heavy metals quantum dots ${ }^{77}$.

Moreover, C-dots are general non-toxic, possessing an overwhelming advantage over semiconductor quantum dots. For example, when 4, 7, 10-trioxa-1,13-tridecanediamine (TTDDA) passivated gC-dots were incubated ${ }^{79}$ at concentration levels below $500 \mathrm{mg} \mathrm{mL}^{-1}$ with HeLa cells for $24 \mathrm{~h}$, the cell viability exceeds $90 \%$. Similarly, addition of gC-dots to the culture medium containing human kidney cells did not induce significant cytotoxicity ${ }^{80}$, 
while no obvious organ damage was observed for mice treated with carboxylated $\mathrm{gC}$-dots ${ }^{81}$. PEG-passivated gC-dots at high concentrations are relatively toxic to cancer cells, but this effect stems from the passivation agent itself rather than the carbogenic core ${ }^{82}$ (Figure 13a). Moreover, a series of studies indicate that incubation with aC-dots has a minimal impact to the viability of HeLa cells (incubation period 24h and 74 h) ${ }^{56,78}$ (Figure 13b) and to HT 29 cells (incubation period $24 \mathrm{~h})^{48}$.

\subsection{Energy applications}

\subsubsection{Catalytic activity}

Amorphous carbon/silica nanocomposites with a high density of sulfonic groups function as environmentally benign, acid solid state catalysts. In particular, sulfonated aC-dots/SiO catalyse the dimerization of a-methylstyrene ${ }^{83}$, esterification of acetic acid with n-butanol ${ }^{84}$ and degradation of cellulose into glucose ${ }^{85}$.

Photogenerated electrons in gold or platinum coated C-dots are trapped in the metallic interface and can catalyse challenging photoreductions. Specifically, gold doped aC-dots and $\mathrm{gC}$-dots are effective catalysts for the conversion of carbon dioxide into formic $\operatorname{acid}^{46}$ and the photocatalytic splitting of water to hygrogen ${ }^{86}$.

Highly PL C-dots anchored to $\mathrm{TiO}_{2}$ extend the range of visible spectrum harnessed by the nanoparticles. Upon illumination of $\mathrm{gC}-\mathrm{dot} / \mathrm{TiO}_{2}$ or $\mathrm{gC}-\operatorname{dot} / \mathrm{SiO}_{2}$ hybrid catalysts, the upconverted radiation excites $\mathrm{TiO}_{2}$ or $\mathrm{SiO}_{2}$ to generate electron/hole pairs. The electron/hole pairs react with absorbed oxidants $\left(\mathrm{O}_{2}\right.$ or $\left.\mathrm{OH}-\right)$ to produce active oxygen radicals which expedite the decomposition of dyes ${ }^{25}$. The electrons are shuttled freely within the carbon network and are injected to $\mathrm{TiO}_{2}$ or $\mathrm{SiO}_{2}$ (the relative position of the band edge permits such an electron injection), inducing and stabilizing charge separation. Similarly, porous gC- 
dot $/ \mathrm{SiO}_{2}$ nanocomposites show catalytic capability for photoenhanced hydrocarbon selective oxidation $^{87}$.

In analogy, gC-dots/ $\mathrm{Fe}_{2} \mathrm{O}_{3}$ and $\mathrm{gC}$-dots/ $\mathrm{ZnO}$ composites ${ }^{88,89}$ exhibit enhanced photocatalytic activity for the degradation of toxic gas under visible light. The overall effect is attributed to three factors: upconversion, the excellent electron donating capability of gC-dots and the strong $\pi-\pi$ interactions between the aromatic rings of the pollutants and the $\mathrm{sp}^{2}$ domains of the nanoparticles.

Catalysts for fuel cells

Inexpensive $\mathrm{N}$-doped carbogenic nanomaterials catalyze the, otherwise slow, ORR that remains a major challenge for the advancement of fuel cells. The cyclic voltammograms (CV) for ORR at $\mathrm{N}$-doped aC-dots electrodes ${ }^{37}$ (in $\mathrm{O}_{2}$ saturated $\mathrm{KOH}$ solution) revealed a cathodic reduction peak at around $0.35 \mathrm{~V}$, although the effect was rather limited compared to standard Pt/C catalysts. At the same time, the $\mathrm{CV}$ at $\mathrm{N}$-doped $\mathrm{gC}$-dots electrodes ${ }^{63}$ show a ORR onset potential at $-0.16 \mathrm{~V}$ with a reduction peak at -0.27 (Figure $14 \mathrm{a}$ ), and the catalytic effect is comparable to that achieved by commercial Pt/C catalysts (Figure 14b). Significantly, N-doped gC-dots fully retained their catalytic activity in the presence of methanol, while metal based catalysts fail to so. In other words, N-doped gC-dots exhibit unprecedented tolerance against methanol crossover and can contribute towards the advancement and commercialization of fuel cells. It is conceivable that incorporation of $\mathrm{N}$ atoms to carbogenic materials creates charged sites that enhance the adsorption of $\mathrm{O}_{2}$. The introduction of nitrogen not only increases the charge mobility of the graphitic lattice, but also lowers the energy band gap. Theoretical calculations suggest that the maximum charge mobility is encountered in carbon atoms with pyrrole nitrogen-containing groups at the edges 
of graphene planes and those with pyrrole nitrogen atoms in combination with 'valley' nitrogen atoms ${ }^{90}$.

\subsubsection{Solar cells}

C-dots as the sensitizer

Owing to their unique PL properties C-dots act as sensitizers in solar cells, effectively replacing standard ruthenium complexes based dyes. In a proof of concept demonstration, colloidal stable GQ-dots containing $168 \pi$-conjugated carbon atoms (derived via all-organic chemistry) were shown to exhibit molar extinction coefficient $\varepsilon_{\mathrm{m}}=1.0 \times 10^{5} \mathrm{M}^{-1} \mathrm{~cm}^{-1}$, nearly an order of magnitude larger than the metal complexes commonly used in similar applications. Moreover, the absorption spectra includes the $900 \mathrm{~nm}$ limit, the optimal energy threshold that enables the thermodynamic limit of energy conversion efficiency in photovoltaic cells ${ }^{17}$. The GQ-dots were used to stain a nanocrystalline $\mathrm{TiO}_{2}$ film for a solar cell assembly where they induced a significant sensitizing effect ${ }^{17}$.

In another study ${ }^{61}$, the gC-dots (derived by dehydration g-butyrolactone) sensitised solar cell show a short-circuit current density $\left(\mathrm{J}_{\mathrm{sc}}\right)$ of $0.53 \mathrm{~mA} \mathrm{~cm}^{-2}$ and an open-circuit voltage $\left(\mathrm{V}_{\mathrm{oc}}\right)$ of $0.38 \mathrm{~V}$ with a fill factor $(\mathrm{FF})$ of 0.64 , for a power conversion efficiency of $0.13 \%$. Indium tin oxide photoelectrodes spin-coated with aC-dots generated reasonable photocurrents, but their pegylated analogues resulted in twice higher intensity ${ }^{91}$.

$\mathrm{gC}$-dots as electron acceptors in organic photovoltaic cells

In organic photovoltaic cells, GQ-dots improve the electron acceptor capability and, thereby, the power efficiency. To that end, a solar cell assembly of ITO/PEDOT:PSS/P3HT:GQdots/Al, (ITO, PEDOT, PSS and P3HT stand for indium tin oxide, poly(3,4ethylenedioxythiophene), poly(styrenesulfonate) and poly(3-hexylthiophene), respectively) 
outperforms (more than 2 orders of magnitude improvement) its GQ-dot free analogue in terms of power conversion efficiency and sort-circuit current. Incorporation of GQ-dots not only affords extensive p-n interfaces for charge separation, but also facilitates the transport of charge carriers within their highly conductive infrastructure ${ }^{29}$ (Figure 15).

In another demonstration ${ }^{92}$, P3HT/ANI-gC-dots (ANI-gC-dot stands for aniline functionalised gC-dot) based organic solar cell show improved efficiency compared to P3HT/ANI-GSs (ANI-GS stands for aniline functionalised graphene sheets). The effect points out to the improved morphology of the $\mathrm{gC}$-dots based film that results in enhanced exciton migration to the donor/acceptor interface and lower internal resistance. In particular, gC-dots based films shows nanoscale phase separation and fine structural elements, as opposed to GSs based film that displays large domains (about 100-200 nm diameter) indicating phase separation at a scale much larger than the diffusion length of excitons (10 nm) (Figure 16).

A poly(3-hexylthiophene):[6,6]-phenyl-C61-butyric acid methyl ester based bulk heterojunction solar cell, achieved improved power conversion efficiency by $12 \%$ due to the integration of a luminescence down-shifting layer containing $\mathrm{gC}$-dots (derived hydrothermally and protected against self-aggregation $)^{93}$.

An ultrasensitive, all carbon photo-detector has been constructed by selective deposition of a layer of GQ-dots to graphene sheets ${ }^{94}$. The remarkable photocurrent responsivity and detectivity observed for the all carbon detector has been attributed to the synergy of three parameters: the large optical absorptivity of GQ-dots, the efficient separation of photogenerated electron-hole pairs due to the band alignment across the GQ-dots /graphene sheet interface and the highly conductive channels of graphene.

\section{Conclusions}


C-dots demonstrate significant potential as low-cost photoluminescence nanoemitters with tuneable structure and functionalities. Both graphitic and amorphous of C-dots share common characteristics such as non-toxic nature, excitation wavelength dependent emission, upconversion, while their PL intensity is selectively quenched in the presence of certain compounds providing a platform for their detection. Moreover, aC-dots/SiO with sulfonic groups are green, solid acid catalysts, while gC-dots $/ \mathrm{SiO}_{2}$ (and their $\mathrm{TiO}_{2}, \mathrm{SiO}_{2}$ $\mathrm{Fe}_{2} \mathrm{O}_{3}, \mathrm{ZnO}$ based counterparts) exhibit enhanced photocatalytic activity for the degradation of toxic compounds under visible light. Au or Pt coated aC-dots and $\mathrm{gC}$-dots function as electron reservoirs, catalysing challenging photoreductions. In fuel cells, N-doped gC-dots are promising methanol tolerant electrocatalysts for the ORR. In solar cells, gC-dots induce significant sensitizing effects and they also function as electron acceptors, improving the power conversion efficiency. 


\section{Figures}

Figures 1. Cartoon demonstrating the generation of graphitic and amorphous C-dots from everyday activities.

Figure 2. a) GQ-dots derived via cage opening of fullerenes: i. Adsorption of $\mathrm{C}_{60}$ molecules to the terraces of Ru crystals; ii. Temperature dependent growth of GQ-dots with triangular and hexagonal equilibrium shape; iii. and iv. Scanning Tunneling Microscope images of the triangular and hexagonal GQ-dots, respectively. Reprinted with permission from Nature Nanotechnology (Reference 15). Copyright (2011) Macmillan Publishers Ltd.

b) GQ-dots produced by all-organic synthesis: i. structure of QC-dots; ii. bulky moieties chemically attached to the edges of the dot to enhance colloidal stability; iii. an energyminimized configuration of QC-dot. Reprinted with permission from Nano Lett. (Reference 17). Copyright (2010) American Chemical Society.

Figure 3. a) A proposed mechanism for the production of $\mathrm{gC}$-dots via oxidative splitting of a graphitic plane. Reprinted with permission from Nano Lett. (Reference 20). Copyright (2012) American Chemical Society.

b) A typical electrochemical cell used for the production of gC-dots. Reprinted with permission from J. Am. Chem. Soc. (Reference 24). Copyright (2009) American Chemical Society.

Figure 4. gC-dots derived by electrooxidation of a graphene film: a and b) TEM images, c) size distribution, d) AFM image on a Si substrate, e) The height profile along the line in $d, f$ ) XRD pattern compared to the initial graphene film, g) Raman spectrum, h) XPS spectra compared to the initial graphene film, i) $\mathrm{C}$ 1s peak compared to paternal film; the inset refers to the $\mathrm{C} 1 \mathrm{~s}$ of $\mathrm{g}$ C-dot. Reprinted with permission from Adv. Mater. (Reference 29). Copyright (2011) John Wiley \& Sons, Inc. 
Figure 5. gC-dots derived by alkali-assisted electrooxidation of graphite rod: a) TEM image, b) fluorescent microscopy images with an excitation wavelength of $360 \mathrm{~nm}$ (scale bar: 50 $\mathrm{mm}$ ), c-h) HRTEM images of typical nanoparticles with different diameters (scale bar: 2 nm), i) Raman spectrum. Reprinted with permission from Angew. Chem. Int. Ed. (Reference 25). Copyright (2010) John Wiley \& Sons, Inc.

Figure 6. aC-dots derived by thermal treatment of octadecylammonium citrate salt: a) TEM images, b) size distribution, c) XRD pattern d) I.R. spectrum. Reprinted with permission from Small (Reference 49). Copyright (2008) John Wiley \& Sons, Inc.

Figure 7. Progressive evolution of a series of photoactive spices based on controlled pyrolysis of a mixture of CA and ethanolamine. Reprinted with permission from J. Am. Chem. Soc. (Reference 57). Copyright (2012) American Chemical Society.

Figure 8. a) Typical sized gC-dots (derived from alkali assisted electrooxidation) optical images illuminated under white (left; daylight lamp) and UV light (right; $365 \mathrm{~nm}$ ), b) PL spectra of typical sized gC-dots: the red, black, green, and blue lines are the PL spectra for blue-, green-, yellow-, and red-emission gC-dots, respectively, c) relationship between the gC-dot size and the PL properties, d) HOMO-LUMO gap dependence on the size of the graphitene fragment. Reprinted with permission from Angew. Chem. Int. Ed. (Reference 25). Copyright (2010) John Wiley \& Sons, Inc.

Figure 9. Deconvolution of PL spectra of GO at various reduction times $t_{\text {red }}$ a) $t_{\text {red }}=0 \min b$ ) $t_{\text {red }}=75$ min, c) $t_{r e d}=180 \mathrm{~min}$ ). d) schematic depiction of the evolution of $\mathrm{sp}^{2}$ islands via chemical reduction of GO. Reprinted with permission from Angew. Chem. Int. Ed. (Reference 72). Copyright (2012) John Wiley \& Sons, Inc.

Figure 10. The excitation wavelength dependent PL spectra of aqueous dispersions of: a) gC-dots (via electrooxidation of a graphene film) Reprinted with permission from Adv. Mater. (Reference 29). Copyright (2011) John Wiley \& Sons, Inc. b) aC-dots (via pyrolytic 
treatment of crude biomass). The excitation wavelength was varied from 350 to $600 \mathrm{~nm}$ with a fixed increment of $25 \mathrm{~nm}$. Reprinted with permission from Green Chem. (Reference 44). Copyright (2012) Royal Society of Chemistry

Figure 11. Upconversion PL spectra of aqueous dispersions of: a) gC-dots (via alkali assisted electrooxidation). Reprinted with permission from Angew. Chem. Int. Ed. (Reference 25). Copyright (2010) John Wiley \& Sons, Inc. b) aC-dots (vis ultrasonic treatment of glucose). Reprinted with permission from Carbon (Reference 74). Copyright (2011) Elsevier.

Figure 12. Two-photon luminescence image of human breast cancer MCF-7 cells with internalized C-dots. Reprinted with permission from J. Am. Chem. Soc (Reference 76). Copyright (2007) American Chemical Society.

Figure 13. Viability of: a) Human cancer cells incubated with $\mathrm{PEG}_{1500^{-}}$passivated gC-dots (black columns) compared to the passivation agent $\mathrm{PEG}_{1500}$ (white columns). Reprinted with permission from J. Phys. Chem. C (Reference 82). Copyright (2009) American Chemical Society. b) HeLa cells incubated for $24 \mathrm{~h}$ with polyethylenimine derived aC-dots. Reprinted with permission from Carbon (Reference 56), Copyright (2013) Elsevier.

Figure 14. Cyclic voltamogramms (reference electrode $\mathrm{Ag} / \mathrm{AgCl}$ ) for Oxygen Reduction Reaction of: a) N-doped gC-dots and b) commercial Pt/C electrodes in $\mathrm{N}_{2}$ and $\mathrm{O}_{2}$ saturated $0.1 \mathrm{M} \mathrm{KOH}$ and $\mathrm{O}_{2}$ saturated $3 \mathrm{M}$ in $\mathrm{CH}_{3} \mathrm{OH}$. Reprinted with permission from J. Am. Chem. Soc. (Reference 63). Copyright (2012) American Chemical Society.

Figure 15. Schematic a) and energy band b) diagrams of the ITO/PEDOT:PSS/P3HT:GQDs/Al device. c) $\mathrm{J}-\mathrm{V}$ characteristic curves for the ITO/PEDOT:PSS/P3HT/Al, ITO/PEDOT:PSS/P3HT:GQDs/Al and ITO/PEDOT:PSS/P3HT: GQDs/Al devices after annealing at $140^{\circ} \mathrm{C}$ for $10 \mathrm{~min}$, single log scale. Reprinted with permission from Adv. Mater. (Reference 29) Copyright (2011) John Wiley \& Sons, Inc. 
Figure 16. AFM images of: a) P3HT/ANI-gC-dots; b) P3HT/ANI- gC-dots; c) MEHPPV/MB- gC-dots; d) J-V curves of the photovoltaic devices based on ANI-gC-dots with different nanoparticle content compared to the best performing ANI-GS based counterpart annealed at $160{ }^{\circ} \mathrm{C}$ for $10 \mathrm{~min}$, in $\mathrm{AM} 1.5 \mathrm{G} 100 \mathrm{~mW}$ illumination. Reprinted with permission from J. Am. Chem. Soc. (Reference 92). Copyright (2011) American Chemical Society. 


\section{References}

1. X. Xu, R. Ray, Y. Gu, H. J. Ploehn, L. Gearheart, K. Raker, W. A. Scrivens: Electrophoretic analysis and purification of fluorescent single-walled carbon nanotube fragments. J. Am. Chem. Soc. 126, 12736 (2004)

2. K. S. Novoselov, A. K. Geim, S. V. Morozov, D. Jiang, Y. Zhang, S. V. Dubonos, I. V. Grigorieva, A. A. Firsov: Electric field effect in atomically thin carbon films. Science 306, $666(2004)$

3. H.W. Kroto, J.R. Heath, S.C. O’Brien, R.F. Curl, R.E. Smalley: C60: Buckminsterfullerene. Nature 318, 162 (1985)

4. S. Iijima: Helical microtubules of graphitic carbon. Nature 354, 56 (1991)

5. S. N. Baker, G.A. Baker: Luminescent carbon nanodots: emergent nanolights. Angew. Chem. Int. Ed. 49, 6726 (2010)

6. J.C.G. E. da Silva, H.M.R. Goncalves : Analytical and bioanalytical applications of carbon dots. Trends in Analytical Chemistry 30, 1327 (2011)

7. H. Li, Z. Kang, Y. Liu, S.-T. Lee: Carbon nanodots: synthesis, properties and applications. J. Mater. Chem. 22, 24230 (2012)

8. J. Shen, Y. Zhu, X. Yang, C. Li: Graphene quantum dots: emergent nanolights for bioimaging, sensors, catalysis and photovoltaic devices. Chem. Commun. 48, 3686 (2012)

9. L. Li, G. Wu, G. Yang, J. Peng, J. Zhao, J.-J. Zhu: Focusing on luminescent graphene quantum dots: current status and future perspectives. Nanoscale, 5, 4015 (2013)

10. P. G. Luo, S. Sahu, S.-T. Yang, S. K. Sonkar, J. Wang, H. Wang, G. E. LeCroy, L. Cao, Y.-P. Sun: Carbon “quantum” dots for optical bioimaging. J. Mater. Chem. B 1, 2116 (2013) 11. Z. Zhang, J. Zhang, N. Chen, L. Qu: Graphene quantum dots: an emerging material for energy-related applications and beyond. Energy Environ. Sci., 5, 8869 (2012) 
12. L. A. Ponomarenko, F. Schedin, M. I. Katsnelson, R. Yang, E. W. Hill, K. S. Novoselov, A. K. Geim: Chaotic dirac billiard in graphene quantum dots. Science, 320, 356 (2008)

13. D. Yongqiang, P. Hongchang, R. Shuyan, C. Congqiang, C.Yuwu, Y. Ting: Etching single-wall carbon nanotubes into green and yellow single-layer graphene quantum dots. Carbon 64, 245 (2013)

\begin{tabular}{|c|c|c|c|c|c|c|c|c|}
\hline 14. T. & Gokus, & R. R. N & & A. Bonetti, & M. Böhmler & A. Lombardo, & K. S. Novoselov & A. $\mathrm{K}$. \\
\hline Geim, & A. C. & Ferrari, & A. & Hartschuh & Making $\mathrm{g}$ & hene lumine & cent by ox & plasma \\
\hline
\end{tabular}
15. J. Lu, P. S. E. Yeo, C. K. Gan, P. Wu K. P. Loh Transforming $\mathrm{C}_{60}$ molecules into graphene quantum dots. Nature Nanotechnology 6, 247 (2011)

16. X. Yan, X. Cui, L. Li: Synthesis of large, stable colloidal graphene quantum dots with tunable size. J. Am. Chem. Soc. 132, 5944 (2010)

17. X. Yan, X. Cui, B. Li, L.-S. Li: Large, solution-processable graphene quantum dots as light absorbers for photovoltaics. Nano Lett. 10, 1869 (2010)

18. H. K. Sadhanala, J. Khateia, K. K. Nanda: Facile hydrothermal synthesis of carbon nanoparticles and possible application as white light phosphors and catalysts for the reduction of nitrophenol RSC Adv. 4, 11481-11485 (2014)

19. Y.-P. Sun, B. Zhou, Y. Lin, W. Wang, K. A. S. Fernando, P. Pathak, M. J. Meziani, B. A. Harruff, X. Wang, H. Wang, P. G. Luo, H. Yang, M. E. Kose, B. Chen, L. M. Veca, S.-Y. Xie: Quantum-sized carbon dots for bright and colorful photoluminescence. J. Am. Chem. Soc. 128, 7756 (2006)

20. J. Peng, W. Gao, B. K. Gupta, Z. Liu, R. Romero-Aburto, L. Ge, L. Song, L. B. Alemany, X. Zhan, G. Gao, S. A. Vithayathil, B. A. Kaipparettu, A. A. Marti, T. Hayashi, J.J. Zhu, P. M. Ajayan: Graphene quantum dots derived from carbon fibers. Nano Lett. 12,844 (2012) 
21. L. Lin, S. Zhan: Creating high yield water soluble luminescent graphene quantum dots via exfoliating and disintegrating carbon nanotubes and graphite flakes. Chem. Commun. 48, 10177 (2012)

22. D. Pan, J. Zhang, Z. Li, M. Wu: Hydrothermal route for cutting graphene sheets into blueluminescent graphene quantum dots. Adv. Mater. 22,734 (2010)

23. J. G. Zhou, C. Booker, R. Li, X. Zhou, T.-K. Sham, X. Sun, Z. Ding: An electrochemical avenue to blue luminescent nanocrystals from multiwalled carbon nanotubes (MWCNTs). J. Am. Chem. Soc. 129, 744 (2007)

24. L. Zheng, Y. Chi, Y. Dong, J. Lin, B. Wang: Electrochemiluminescence of water-soluble carbon nanocrystals released electrochemically from graphite. J. Am. Chem. Soc. 131, 4564 (2009)

25. H. Li, X. He, Z. Kang, H. Huang, Y. Liu, J. Liu, S. Lian, C. H. A. Tsang, X. Yang, S.-T. Lee: Water-soluble fluorescent carbon quantum dots and photocatalyst design. Angew. Chem., Int. Ed. 49, 4430 (2010)

26. X. Yu, R. Liu, G. Zhang, H. Cao: Carbon quantum dots as novel sensitizers for photoelectrochemical solar hydrogen generation and their size-dependent effect. Nanotechnology 24, 335401 (2013)

27. H. Ming, Z. Ma, Y. Liu, K. M. Pan, H. Yu, F. Wang and Z. H. Kang, Large scale electrochemical synthesis of high quality carbon nanodots and their photocatalytic property. Dalton Trans. 41, 9526 (2012)

28. J. Lu, J. Yang, J. Wang, A. Lim, S. Wang, K. P. Loh One-pot synthesis of fluorescent carbon nanoribbons, nanoparticles, and graphene by the exfoliation of graphite in ionic liquids. ACS Nano 3, 2367-2375 (2009) 
29. Y. Li, Y. Hu, Y. Zhao, G. Shi, L. Deng, Y. Hou, L. Qu: An electrochemical venue to Green luminescent graphene quantum dots as potential electron-acceptors for photovoltaics. Adv. Mater. 23, 776 (2011)

30. S. Niyogi, E. Bekyarova, M. E. Itkis, H. Zhang, K. Shepperd, J. Hicks, M. Sprinkle, C. Berger, C. N. Lau, W. A. de Heer, E. H. Conrad, R. C. Haddon: Spectroscopy of covalently functionalized graphene Nano Lett. 10, 4061 (2010)

31. H. Li, X. He, Y. Liu, H. Yu, Z. Kang, S.-T. Lee: Synthesis of fluorescent carbon nanoparticles directly from active carbon via a one-step ultrasonic treatment. Materials Research Bulletin 46, 147 (2011)

32. H. Peng,||J. Travas-Sejdic. Simple aqueous solution route to luminescent carbogenic dots from carbohydrates. Chem. Mater. 21, 5563 (2009)

33. L. Zhou, B. He, J. Huang Amphibious fluorescent carbon dots: one-step green synthesis and application for light-emitting polymer nanocomposites. Chem. Commun. 49, $8078(2013)$

34. S. Liu, J. Tian, L. Wang, Y. Zhang, X. Qin, Y. Luo, A. M. Asiri, A. O. Al-Youbi, X. Sun: Hydrothermal treatment of grass: a low-cost, green route to nitrogen-doped, carbon-rich, photoluminescent polymer nanodots as an effective fluorescent sensing platform for labelfree detection of $\mathrm{Cu}(\mathrm{II})$ ions. Adv. Mater. 24, 2037 (2012)

35. Q. Liang, W. Ma, Y. Shi, Z. Li, X. Yang: Easy synthesis of highly fluorescent carbon quantum dots from gelatine and their luminescent properties and applications. Carbon 60,421(2013)

36. S. Sahu, B. Behera, T. K. Maiti, S. Mohapatra Simple one-step synthesis of highly luminescent carbon dots from orange juice: application as excellent bio-imaging agents.

Chem. Commun. 48, 8835 (2012) 
37. C. Zhu, J. Zhai, S. Dong: Bifunctional fluorescent carbon nanodots: green synthesis via soy milk and application as metal-free electrocatalysts for oxygen reduction. Chem. Commun. 48, 9367 (2012)

38. H. Huang, J.-J. Lv, D.-L. Zhou, N. Bao, Y. Xu, A.-J. Wang, J.-J. Feng: One-pot green synthesis of nitrogen-doped carbon nanoparticles as fluorescent probes for mercury ions. RSC Adv. 3, 21691 (2013)

39. Z. Zhang, J. Hao, J. Zhang, B. Zhang, J. Tang: Protein as the source for synthesizing fluorescent carbon dots by a one-pot hydrothermal route. RSC Adv. 2,8599 (2012)

40. J. Gu, W. Wang, Q. Zhang, Z. Meng, X. Jia, K. Xi: Synthesis of fluorescent carbon nanoparticles from polyacrylamide for fast cellular endocytosis. RSC Advances 3, 15589 (2013)

41. Q. Wang, X. Huang, Y. Long, X. Wang,
Hollow luminescent carbon dots for drug delivery. Carbon 61, 640(2013)

42. R. Liu, D. Wu, S. Liu, K. Koynov, W. Knoll, Q. Li: An aqueous route to multicolor photoluminescent carbon dots, using silica spheres as carriers. Angew. Chem. Int. Ed. 48, 4598 (2009)

43. P.-C. Hsu, Z.-Y. Shih, C.-H. Lee, H.-T. Chang: Synthesis and analytical applications of photoluminescent carbon nanodots. Green Chem. 14, 917 (2012)

44. M.J. Krysmann, A. Kelarakis, E.P. Giannelis: Photoluminescent carbogenic nanoparticles directly derived from crude biomass. Green Chem. 14, 3141(2012)

45. J. Wang, C.-F. Wang, S. Chen: Amphiphilic egg-derived carbon dots: rapid plasma fabrication, pyrolysis process and multicolor printing patterns. Angew. Chem. Int. Ed. 51, $9297(2012)$ 
46. J. Wang, S. Sahu, S. K. Sonkar, K. N. Tackett II, K.W. Sun, Y. Liu, H. Maimaiti, P. Anilkumar, Y.-P. Sun: Versatility with carbon dots - from overcooked BBQ to brightly fluorescent agents and photocatalysts. RSC Adv. 3, 15604 (2013)

47. M. Tan, L. Zhang, R. Tang, X. Song, Y. Li, H. Wu, Y. Wang, G. Lv, W. Liu , X. Maa: Enhanced photoluminescence and characterization of multicolor carbon dots using plant soot as a carbon source. Talanta $\mathbf{1 1 5}, 950(2013)$

48. A. Jaiswal, S. S. Ghosh, A. Chattopadhyay: One step synthesis of C-dots by microwave mediated caramelization of poly(ethylene glycol). Chem. Commun. 48, 407 (2012)

49. A.B. Bourlinos, A. Stassinopoulos, D. Anglos, R. Zboril, M. Karakassides, E.P Giannelis: Surface functionalized carbogenic quantum dots. Small 4, 455 (2008)

50. A. Kelarakis, K. Yoon, I. Sics, R. H. Somani, B. S. Hsiao, B. Chu: Uniaxial deformation of an elastomer nanocomposite containing modified carbon nanofibers by in-situ synchrotron X-ray diffraction. Polymer, 46,5103 (2005)

51. H. Zheng, Q. Wang, Y. Long, H. Zhang, X. Huang, R. Zhu, Enhancing the luminescence of carbon dots with a reduction pathway. Chem. Commun. 47, 10650 (2011)

52. Z. Qian, J. Ma, X. Shan, L. Shao, J. Zhou, J. Chen, H. Feng: Surface functionalization of graphene quantum dots with small organic molecules from photoluminescence modulation to bioimaging applications: an experimental and theoretical investigation. RSC Adv. 3,14571 (2013)

53. Y. P. Sun, X. Wang, F. S. Lu, L. Cao, M. J. Meziani, P. J. G. Luo, L. R. Gu, L. M. Veca: Doped carbon nanoparticles as a new platform for highly photoluminescent dots. J. Phys. Chem. C 112, 18295 (2008)

54. K. Qu, J. Wang, J. Ren, X. Qu: Carbon dots prepared by hydrothermal treatment of dopamine as an effective fluorescent sensing platform for the label-free detection of iron (III) ions and dopamine. Chem. Eur. J. 19, 7243 (2013) 
55. A. B. Bourlinos, M. A. Karakassides, A. Kouloumpis, D. Gournis, A. Bakandritsos , I. Papagiannouli, P. Aloukos, S. Couris, K. Hola, R. Zboril, M. Krysmann, E. P. Giannelis: Synthesis, characterization and non-linear optical response of organophilic carbon dots. Carbon 61,640 (2013)

56. L. Shen, L. Zhang, M. Chen, X. Chen, J. Wang: The production of pH-sensitive photoluminescent carbon nanoparticles by the carbonization of polyethylenimine and their use for bioimaging. Carbon 55,343 (2013)

57. M.J. Krysmann, A. Kelarakis, P. Dallas, E.P. Giannelis: Formation mechanism of carbogenic nanoparticles with dual photoluminescence emission. J. Am. Chem. Soc. 134, $747(2012)$

58. S. Zhu, Q. Meng, L. Wang, J. Zhang, Y. Song, H. Jin, K. Zhang, H. Sun, H. Wang, B. Yang: Highly Photoluminescent Carbon Dots for Multicolor Patterning, Sensors, and Bioimaging. Angew. Chem. Int. Ed. 52, 3953 (2013)

59. H. Zhu, X. Wang, Y. Li, Z. Wang, F. Yang, X. Yang, Microwave synthesis of fluorescent carbon nanoparticles with electrochemiluminescence properties. Chem. Commun. $5118(2009)$

60. F. Wang, Z. Xie, H. Zhang, C. Liu, Y. Zhang: Highly luminescent organosilanefunctionalized carbon dots. Adv. Funct. Mater. 21, 1027 (2011)

61. P. Mirtchev, E. J. Henderson, N. Soheilnia, C. M. Yipc and G. A. Ozin: Solution phase synthesis of carbon quantum dots as sensitizers for nanocrystalline $\mathrm{TiO}_{2}$ solar cells. J. Mater. Chem. 22, 1265 (2012).

62. S.-L. Hu, K.-Y. Niu, J. Sun, J. Yang, N.-Q. Zhao, X.-W. Du: One-step synthesis of fluorescent carbon nanoparticles by laser irradiation. J. Mater. Chem. 19,484 (2009)

63. Y. Li, Y. Zhao, H. Cheng, Y. Hu, G. Shi, L. Dai, L. Qu: Nitrogen-doped graphene quantum dots with oxygen-rich functional groups. J. Am. Chem. Soc. 134, 15 (2012) 
64. D. Sun, R. Ban, P.-H. Zhang, G.-H. Wu, J.-R. Zhang, J.-J. Zhu: Hair fiber as a precursor for synthesizing of sulfur- and nitrogen-co-doped carbon dots with tunable luminescence properties. Carbon 4,424(2013)

65. Y. Dong, H. Pang, H. B. Yang, C. Guo, J. Shao, Y. Chi, C. Ming Li, T. Yu: Carbon-based dots co-doped with nitrogen and sulfur for high quantum yield and excitation-independent emission. Angew. Chem. 125, 7954 (2013)

66. D. Qu, M. Zheng, P. Du, Y. Zhou, L. Zhang, D. Li, H. Tan, Z. Zhao, Z. Xie, Z. Sun:

Highly luminescent S, N co-doped graphene quantum dots with broad visible absorption bands for visible light photocatalysts. Nanoscale 5, 12272 (2013)

67. F. Li, C. Liu, J. Yang, Z. Wang, W. Liu, F. Tian: Mg/N double doping strategy to fabricate extremely high luminescent carbon dots for bioimaging. RSC Adv. 4, 3201 (2014)

68. S. Srivastava, R. Awasthi, D. Tripathi, M. K. Rai, V. Agarwal, V. Agrawal, N. S. Gajbhiye, R. K. Gupta: Magnetic-nanoparticle-doped carbogenic nanocomposite: an effective magnetic resonance/fluorescence multimodal imaging probe. Small 8, 1099 (2012)

69. A. B. Bourlinos, A. Bakandritsos, A. Kouloumpis, D. Gournis, M. Krysmann, E. P. Giannelis, K. Polakova, K. Safarova, K. Holaf, R. Zboril: Gd(III)-doped carbon dots as a dual fluorescent-MRI probe. J. Mater. Chem. 22, 23327 (2012)

70. S. Jahan, F. Mansoor, S. Naz, J. Lei, S. Kanwal: Oxidative synthesis of highly fluorescent Boron/Nitrogen co-doped carbon nanodots enabling detection of photosensitizer and carcinogenic dye. Anal. Chem. 85,10232 (2013)

71. G. Eda, Y.-Y, Lin, C. Mattevi, H. Yamaguchi, H.-A. Chen, I-S. Chen, C.-W. Chen, M. Chhowalla: Blue photoluminescence from chemically derived graphene oxide. Adv. Mater. 22, $505(2010)$

72. C.-T. Chien, S.-S. Li, W.-J. Lai, Y.-C. Yeh, H.-A. Chen, I-S. Chen, L.-C. Chen, K.-H. Chen, T. Nemoto, S. Isoda, M. Chen, T. Fujita, G. Eda, H. Yamaguchi, M. Chhowalla, C.-W. 
Chen: Tunable photoluminescence from graphite oxide. Angew. Chem. Int. Ed. 51, 6662 (2012)

73. L. Cao, M. J. Meziani, S. Sahu, Y.P. Sun: Photoluminescence properties of graphene versus other carbon nanomaterials. Acc. Chem. Res. 46,171(2013)

74. H. Li, X. He, Y. Liu, H. Huang, S. Lian, S.-T. Lee, Z. Kang: One-step ultrasonic synthesis of water-soluble carbon nanoparticles with excellent photoluminescent properties. Carbon 49, 605 (2011)

75. M. Haase, H. Schafer: Upconverting nanoparticles. Angew. Chem. Int. Ed. 2011, 50, 5808 $(2011)$

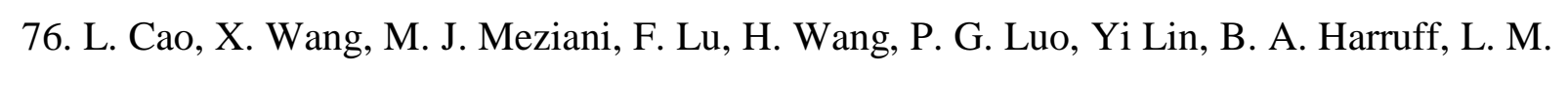
Veca, D. Murray, S.-Y. Xie,||Y.-P. Sun, Carbon dots for multiphoton bioimaging. J. Am. Chem. Soc. 129, $11318(2007)$

\begin{tabular}{ll|l|l|l|l|l|l|} 
77. S.-T. Yang, & L. Cao, & P. G. Luo, & F. Lu, X. Wang, & H. Wang, & M. J. Meziani, & Y. Liu, G. Qi, \\
\hline
\end{tabular}
Ya-Ping Sun 1 Carbon dots for optical imaging in vivo. J. Am. Chem. Soc. 131,11308 (2009) 78. H. Ding, L.-W. Cheng, Y.-Y. Ma, J.-L. Kong, H.-M. Xiong: Luminescent carbon quantum dots and their application in cell imaging. New J. Chem., 37, 2515

79. Y.-Y. Zhang, M. Wu, Y.-Q. Wang, X.-W. He, W.-Y. Li, X.-Z. Feng: A new hydrothermal refluxing route to strong fluorescent carbon dots and its application as fluorescent imaging agent. Talanta 117,196 (2013)

80. Q.-L. Zhao, Z.-L. Zhang, B.-H. Huang, J. Peng, M. Zhang, D.-W. Pang: Facile preparation of low cytotoxicity fluorescent carbon nanocrystals by electrooxidation of graphite. Chem. Commun. 5116 (2008)

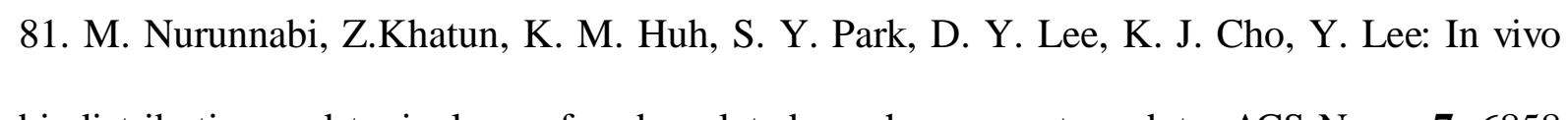
biodistribution and toxicology of carboxylated graphene quantum dots. ACS Nano, 7, 6858 (2013) 
82. S.-T. Yang, X. Wang, H. Wang, F. Lu, P. G. Luo, L. Cao, M. J.Meziani, J.-H. Liu, Y. Liu, M. Chen, Y. Huang, Y.-P. Sun: Carbon dots as nontoxic and high-performance fluorescence imaging agents. J. Phys. Chem. C 113, 18110 (2009)

83. K. Nakajima, M. Okamura, J. N. Kondo, K. Domen, T. Tatsumi, S. Hayashi, M. Hara: Amorphous carbon bearing sulfonic acid groups in mesoporous silica as a selective catalyst.

Chem. Mater. 21, 186 (2009)

84. Y. Liu, J. Chen, J. Yao, Y. Lu, L. Zhang, X. Liu: Preparation and properties of sulfonated carbon-silica composites from sucrose dispersed on MCM-48. Chem. Eng. J. 148, 201 (2009)

85. S. Van de Vyver, L. Peng, J. Geboers, H. Schepers, F. de Clippel, C. J. Gommes, B. Goderis, P. A. Jacobs, B. F. Sels: Sulfonated silica/carbon nanocomposites as novel catalysts for hydrolysis of cellulose to glucose. Green Chem. 12, 1560 (2010)

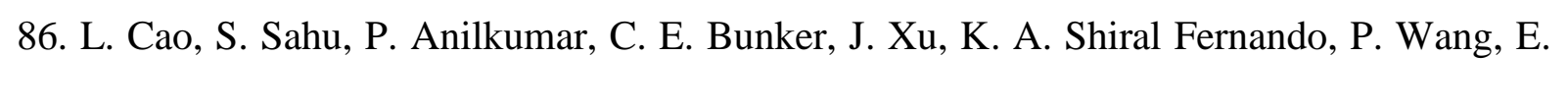

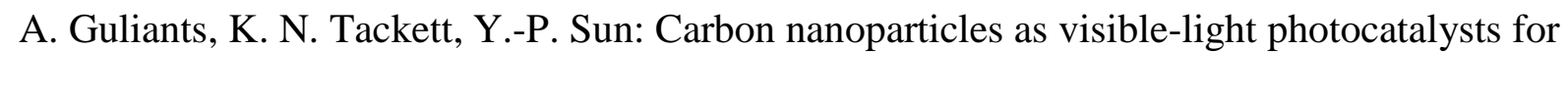
efficient $\mathrm{CO}_{2}$ conversion and beyond. J. Am. Chem. Soc. 133, 4754 (2011)

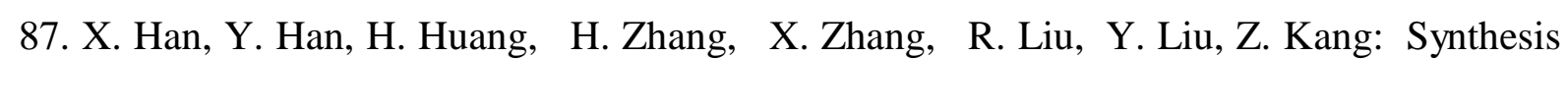
of carbon quantum dots/SiO 2 porous nanocomposites and their catalytic ability for photoenhanced hydrocarbon selective oxidation. Dalton Trans., 42, 10380 (2013)

88. H. C. Zhang, H. Ming, S. Lian, H. Huang, H. Li, L. Zhang, Y. Liu, Z. Kang and S. T. Lee: $\mathrm{Fe}_{2} \mathrm{O}_{3} /$ carbon quantum dots complex photocatalysts and their enhanced photocatalytic activity under visible light. Dalton Trans. 40, 10822 (2011)

89. H. Yu, H. C. Zhang, H. T. Li, H. Huang, Y. Liu, H. Ming, Z. H. Kang: ZnO/carbon quantum dots nanocomposites: one-step fabrication and superior photocatalytic ability for toxic gas degradation under visible light at room temperature. New J. Chem. 36, 1031 (2012) 
90. V. V. Strelko, V. S. Kuts, P. A. Thrower: On the mechanism of possible influence of heteroatoms of nitrogen, boron and phosphorus in a carbon matrix on the catalytic activity of carbons in electron transfer reactions. Carbon 38,1499 (2000)

91. J. Shen, Y. Zhu, X. Yang, J. Zong, J. Zhang, C. Li: One-pot hydrothermal synthesis of graphene quantum dots surface-passivated by polyethylene glycol and their photoelectric conversion under near-infrared light. New J. Chem. 36, 97 (2012)

92. V. Gupta, N. Chaudhary, R. Srivastava, G. D. Sharma, R. Bhardwaj, S. Chand: Luminescent graphene quantum dots for organic photovoltaic devices. J. Am. Chem. Soc. 133, $9960(2011)$

93. J. J. Huang, Z. F. Zhong, M. Z. Rong, X. Zhou, X. D. Chen, M. Q. Zhang: An easy approach of preparing strongly luminescent carbon dots and their polymer based composites for enhancing solar cell efficiency. Carbon 70, 190 (2014)

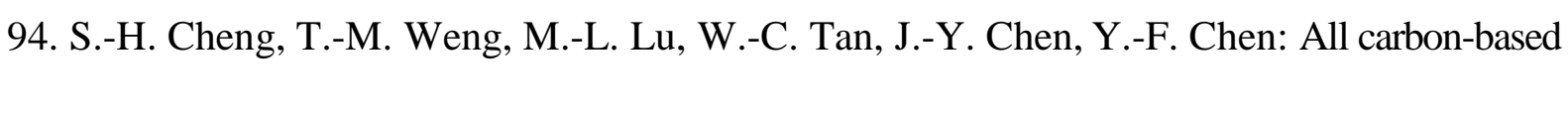
photodetectors: an eminent integration of graphite quantum dots and two dimensional graphene.

Scientific Reports 3, 2694 (2014) 

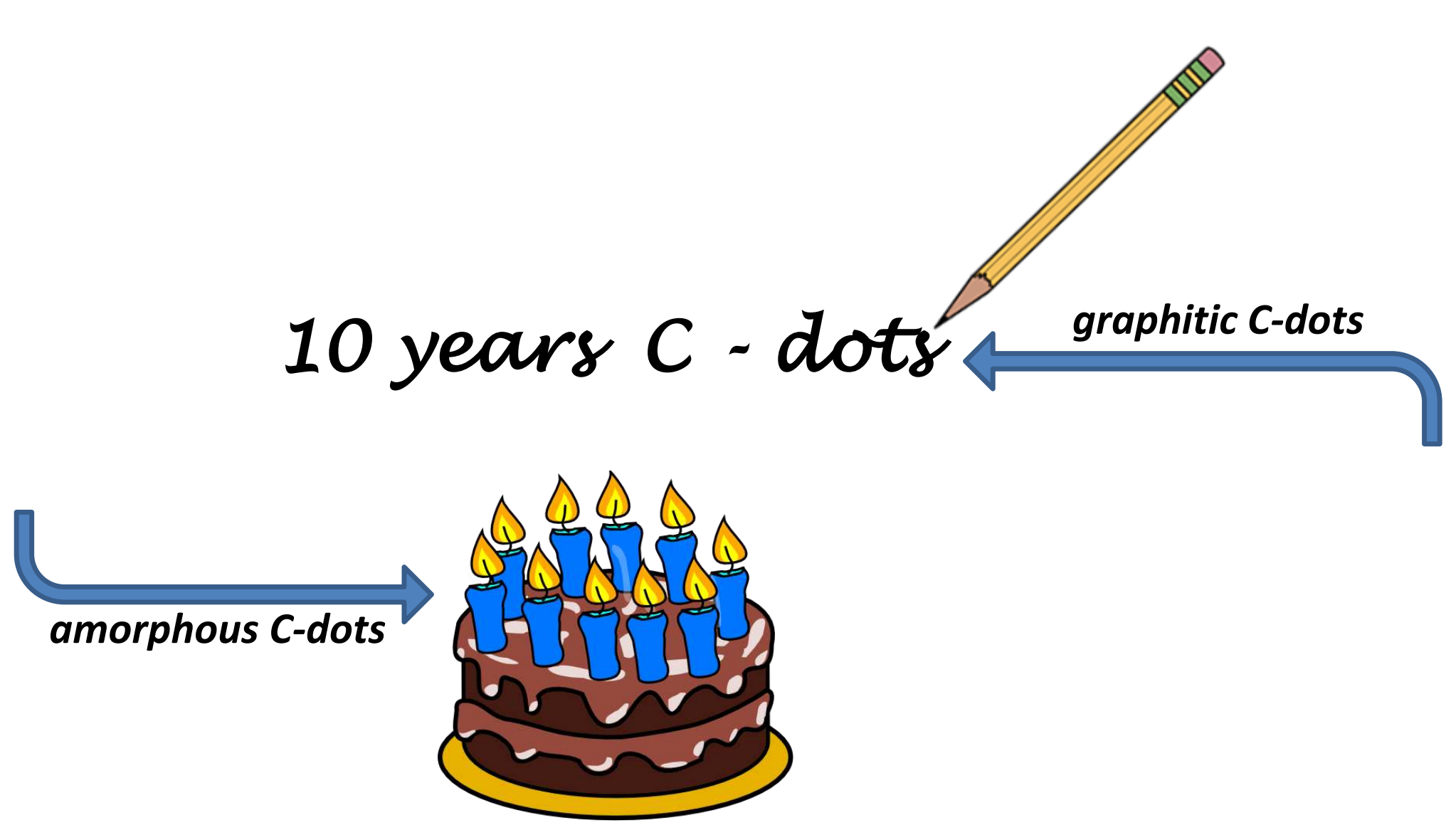

Figure 1 

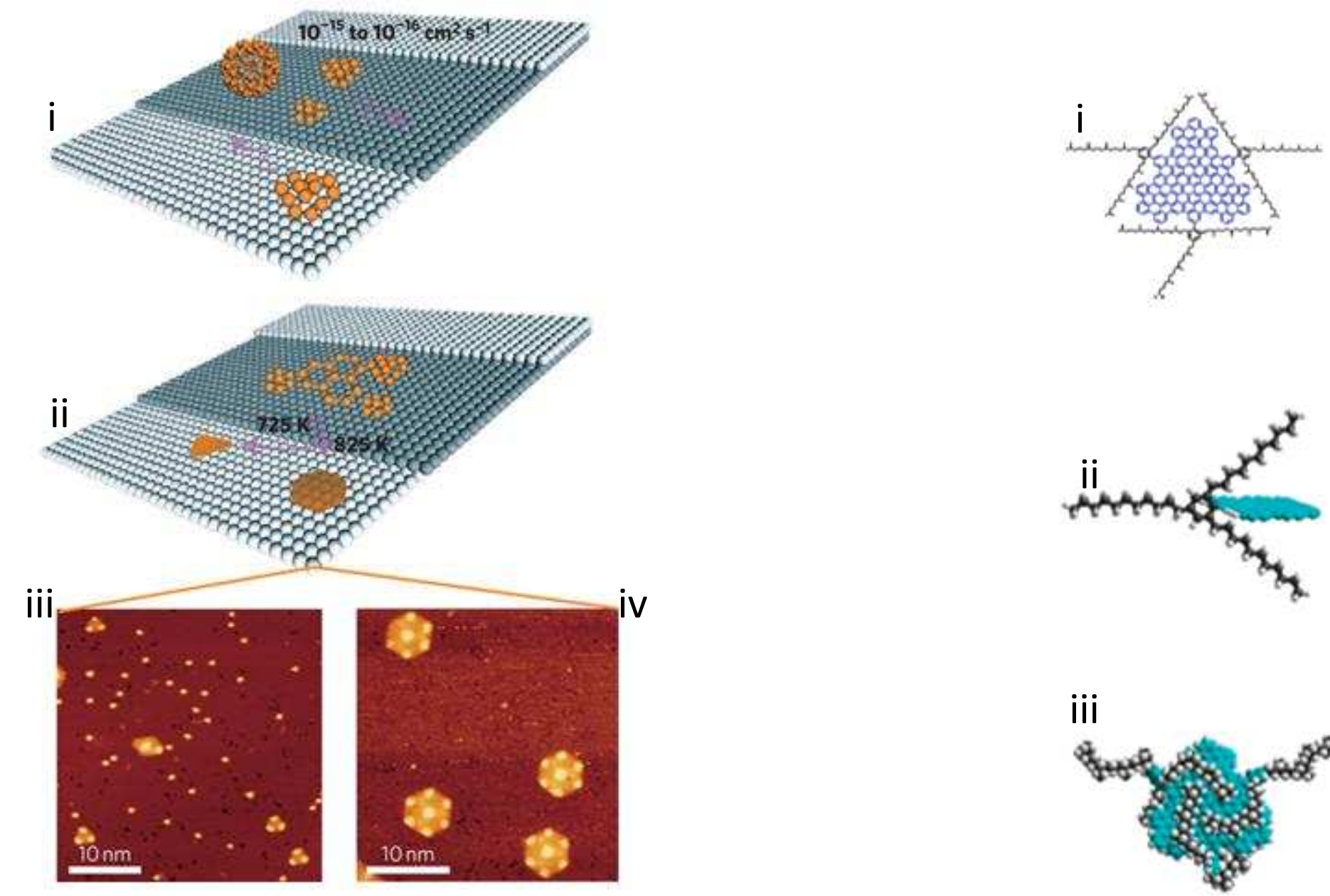

Figure 2 
a

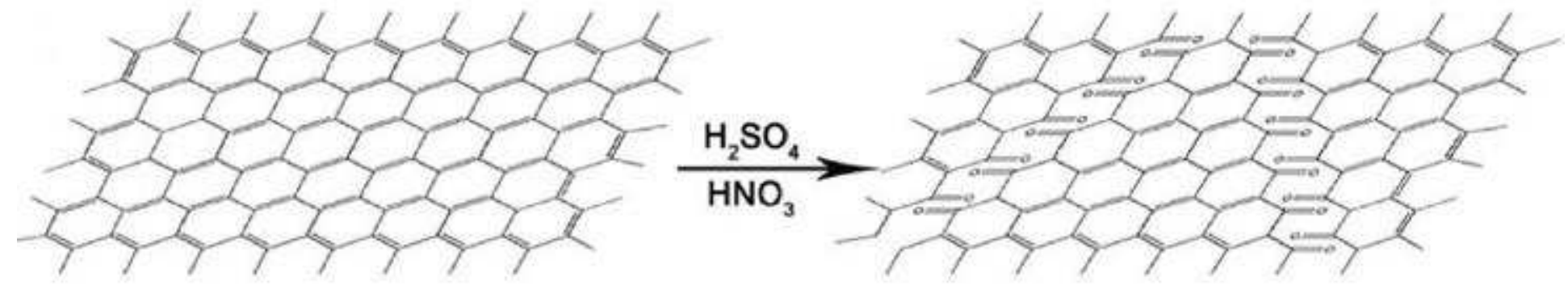

b

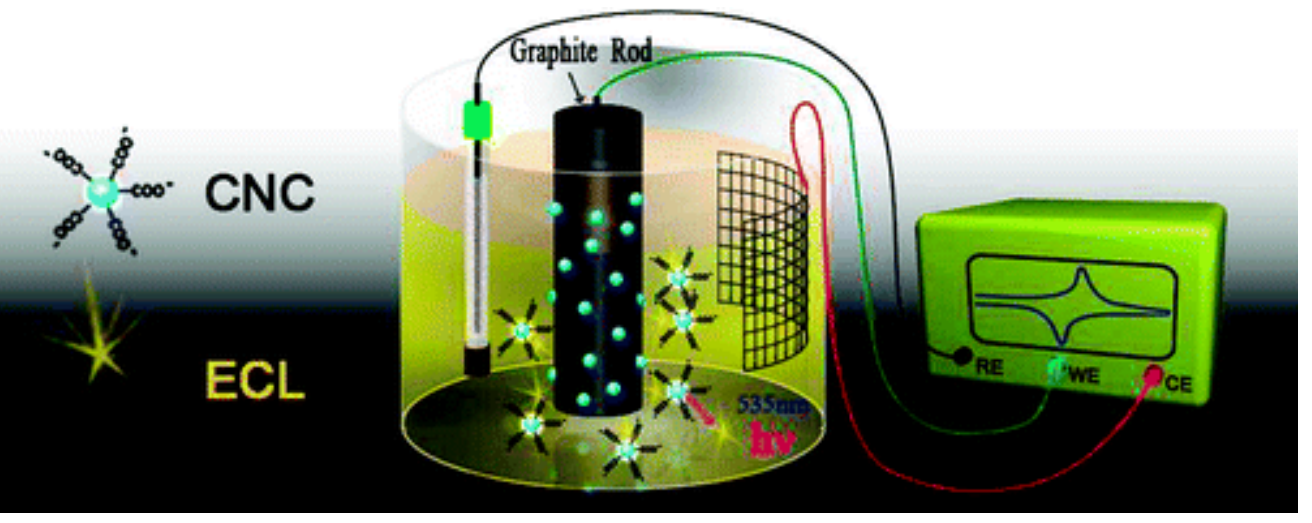

Figure 3 

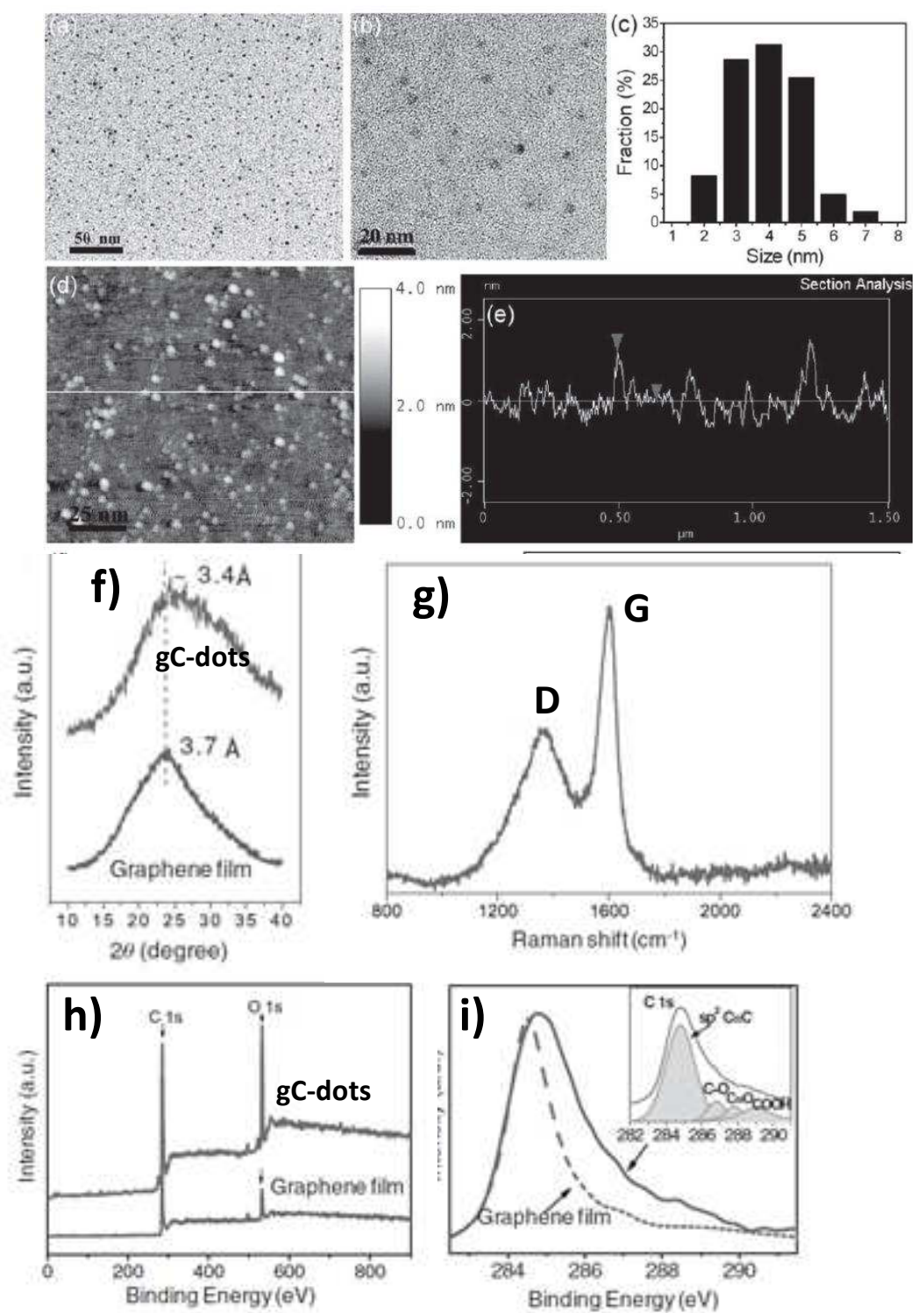

Figure 4 

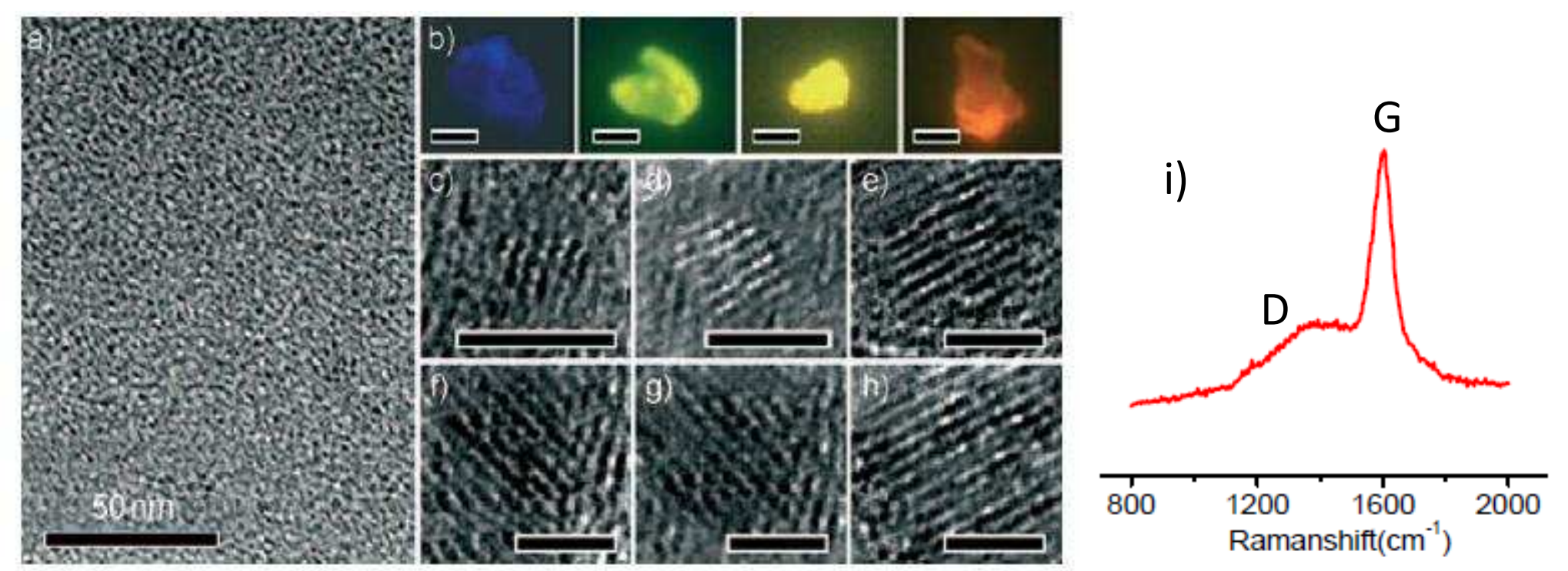

Figure 5 

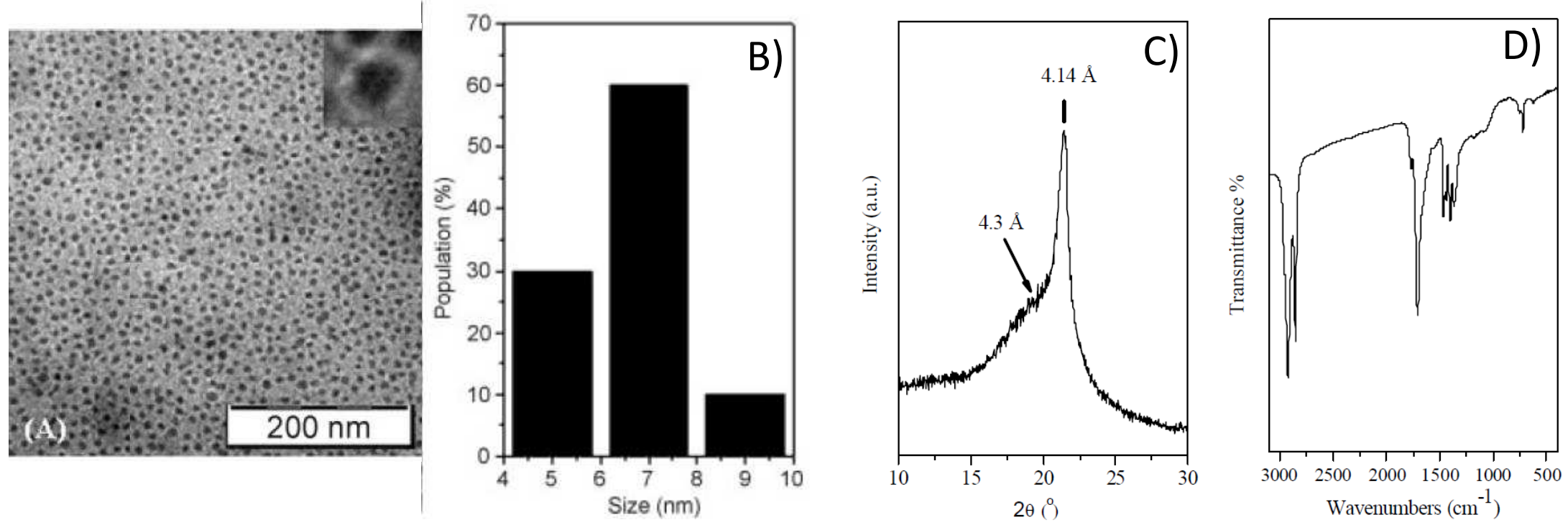

Figure 6 


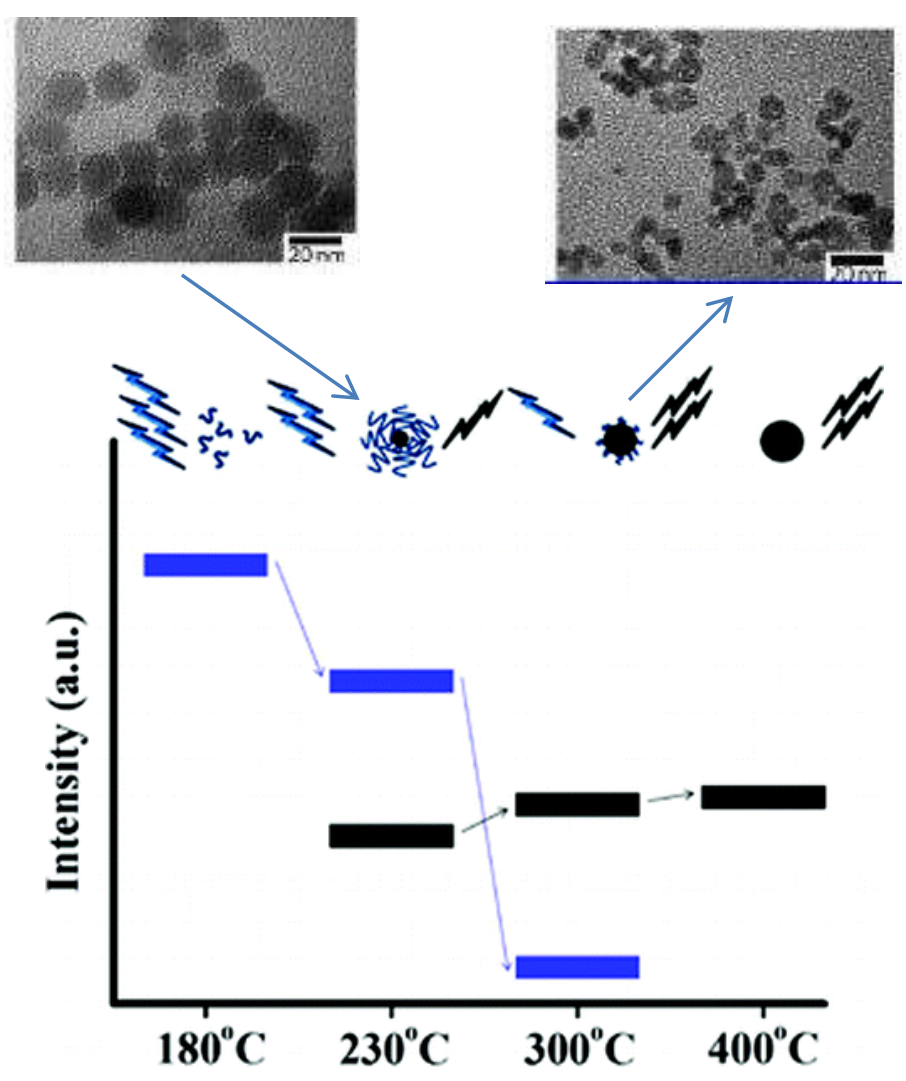

Figure 7 
a)
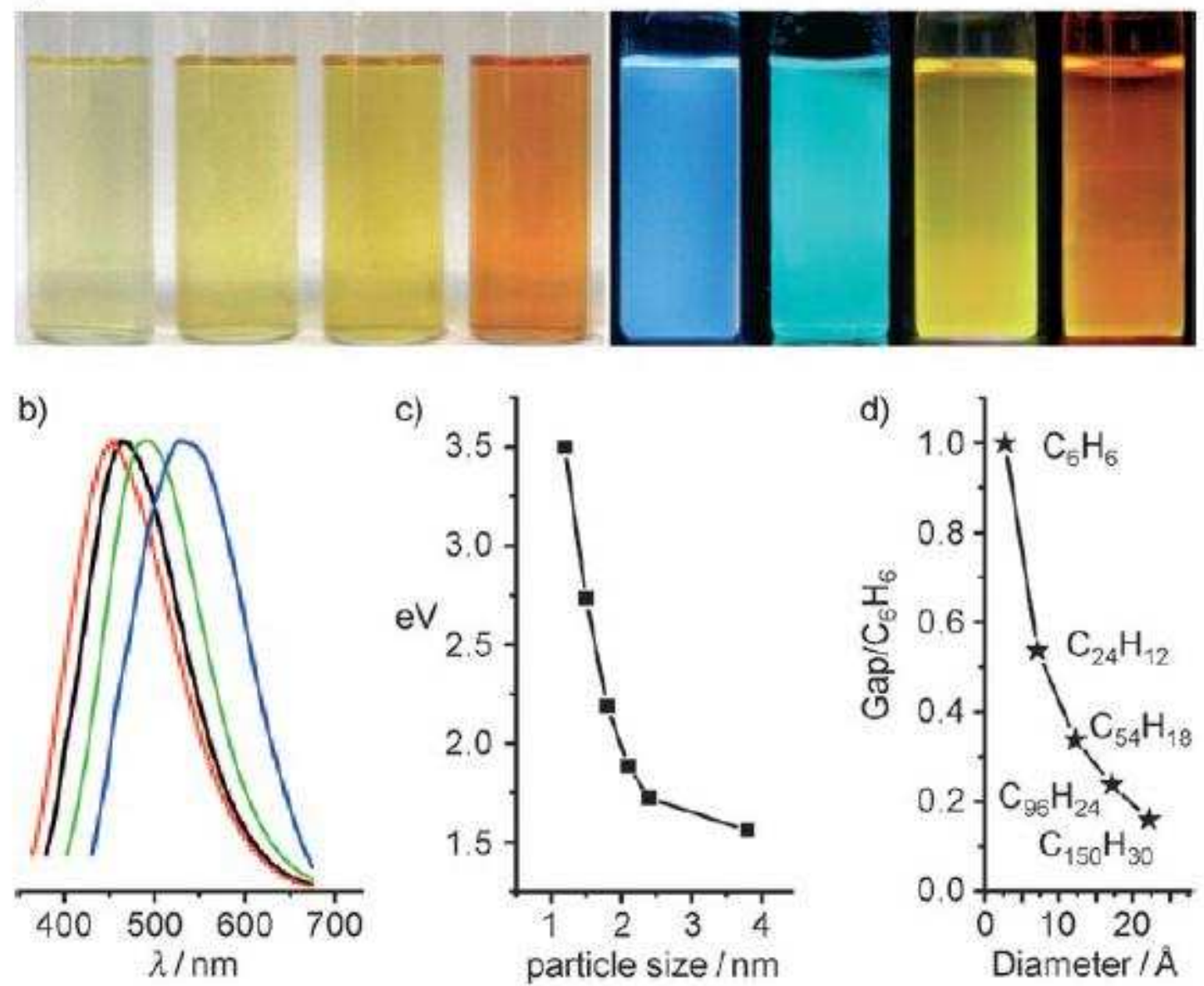

Figure 8 

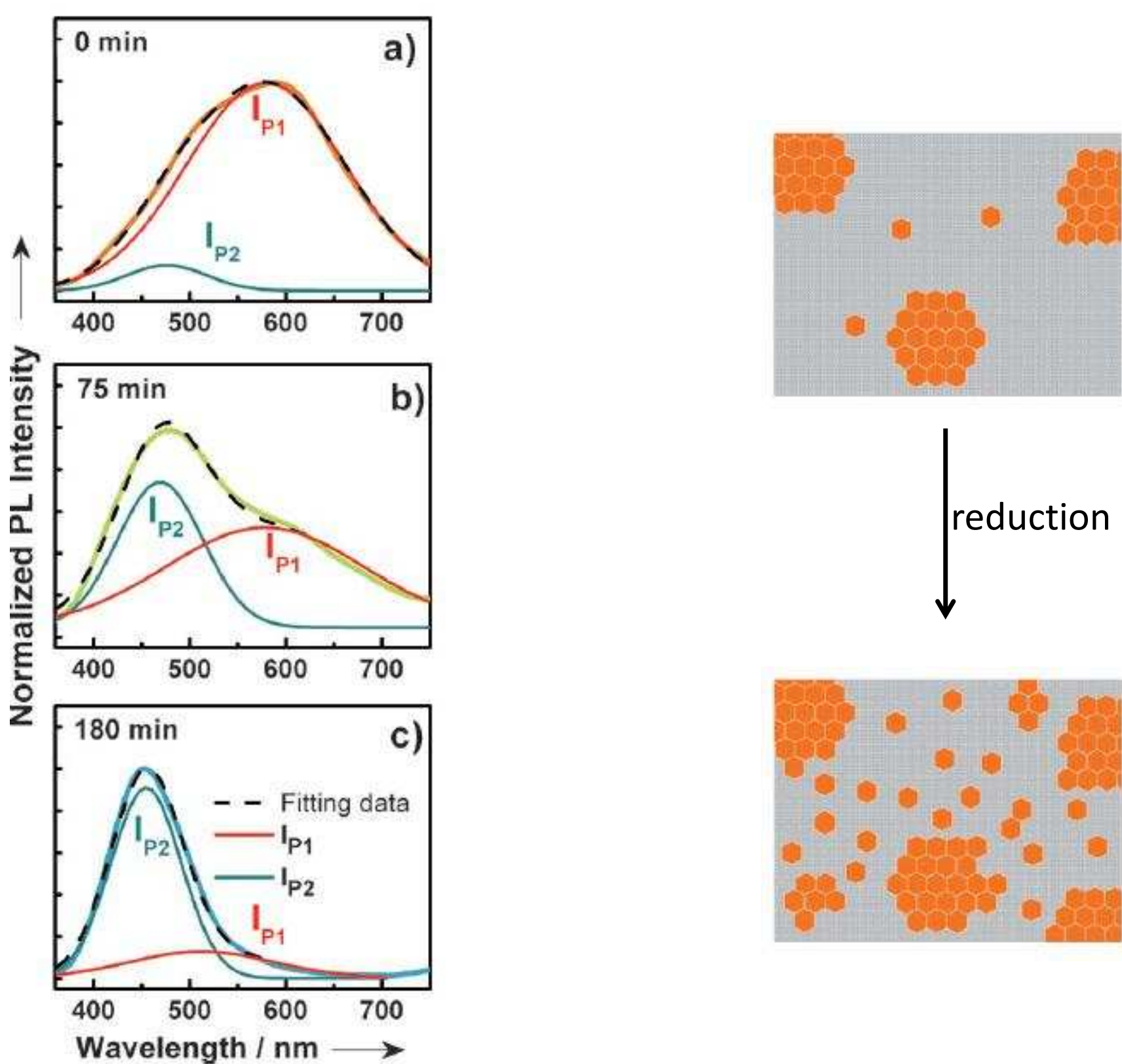

d)

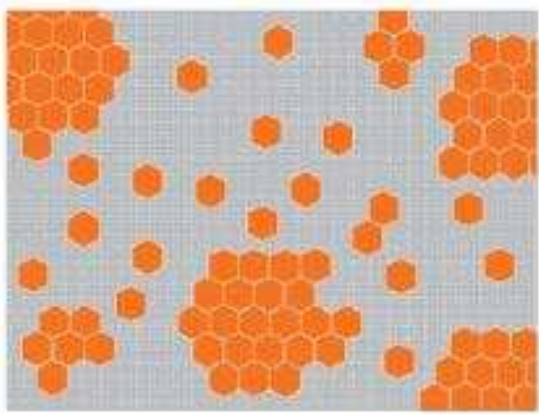

Figure 9 

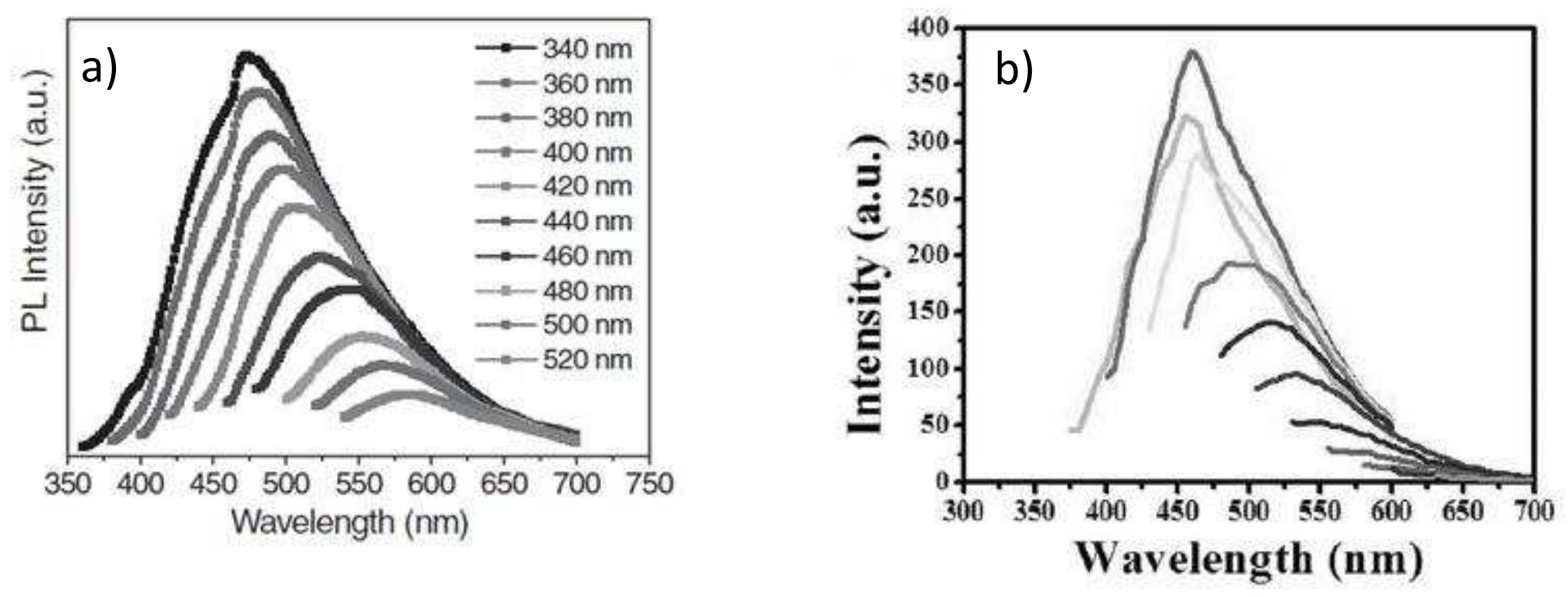

Figure 10 

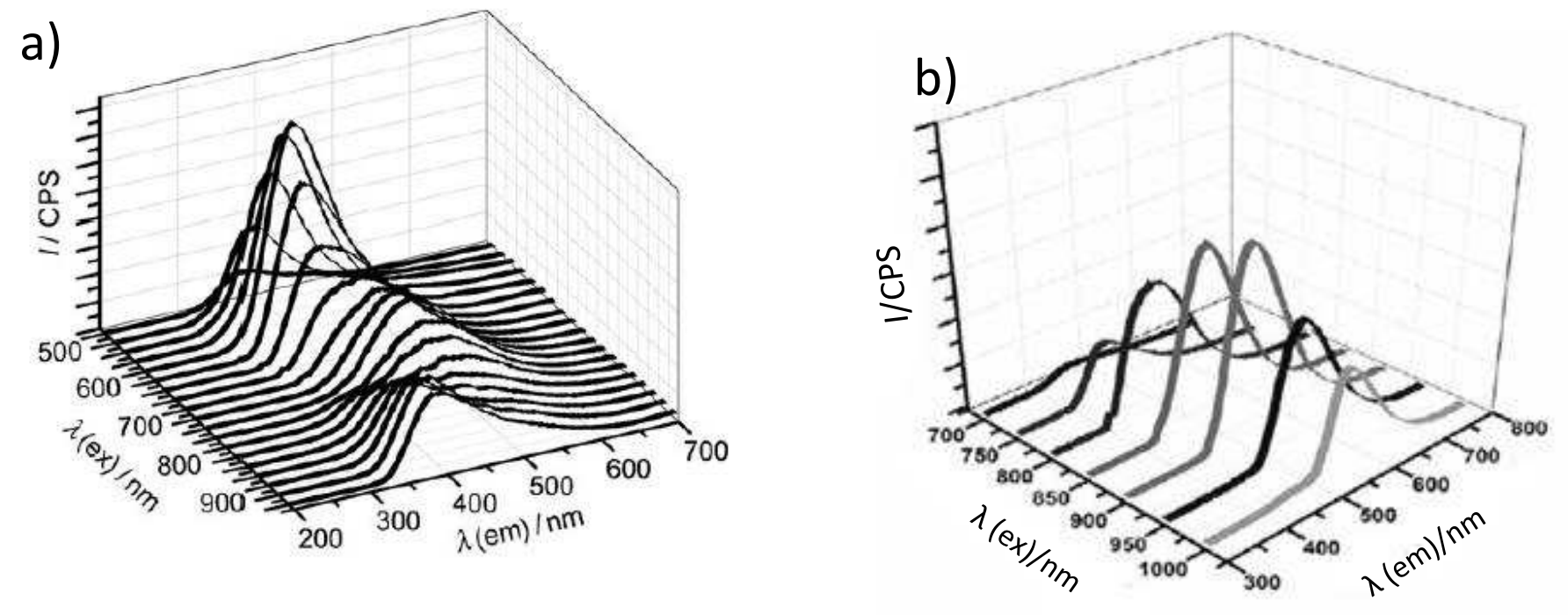

Figure 11 


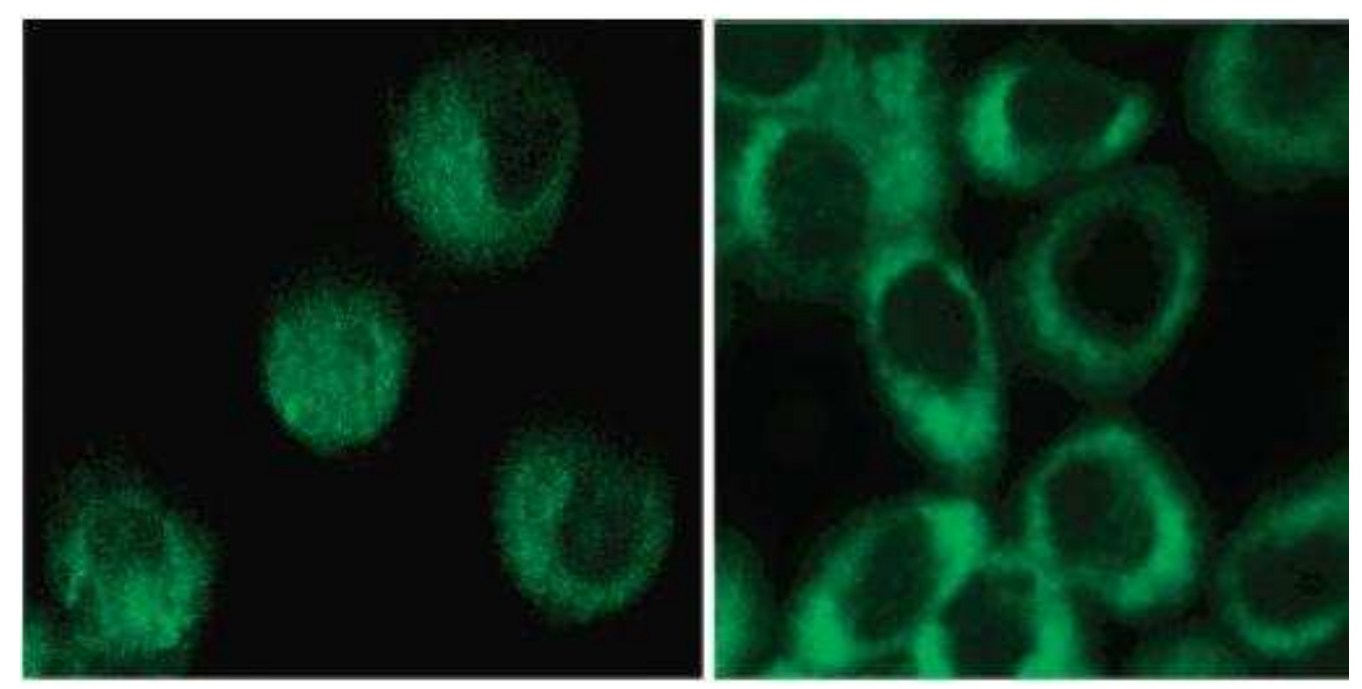

Figure 12 

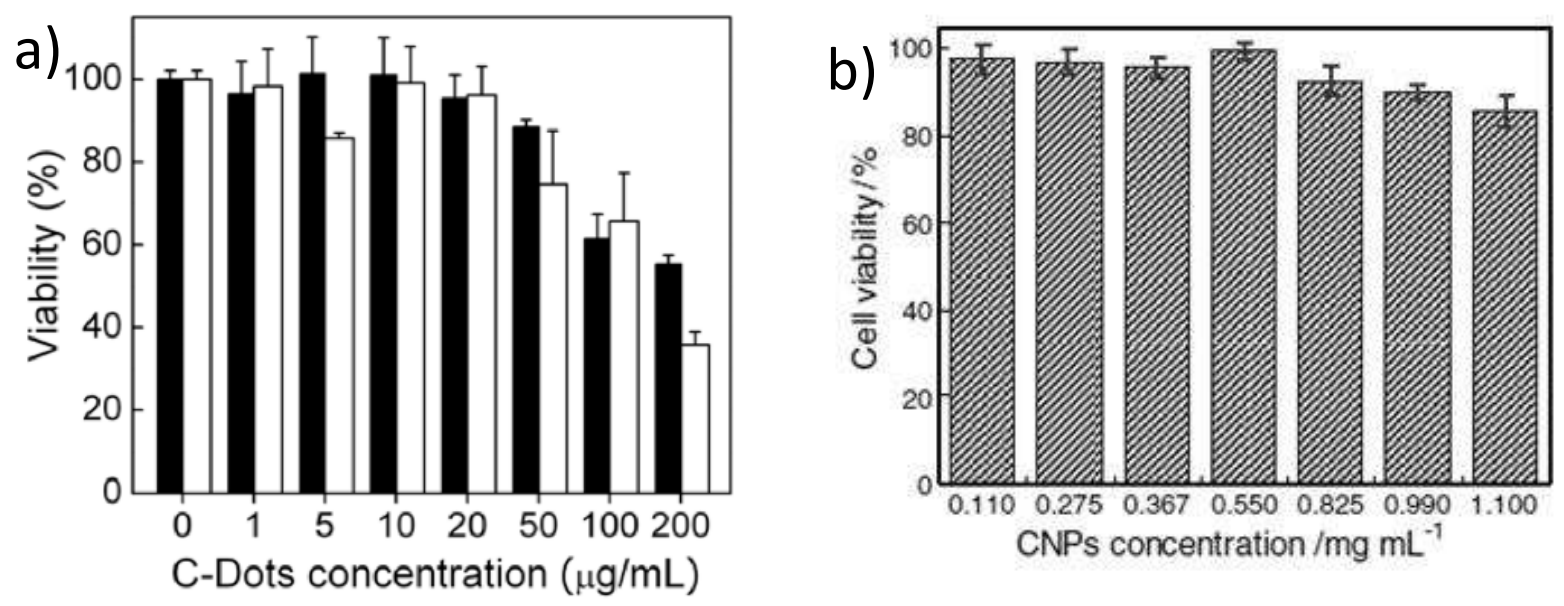

Figure 13 

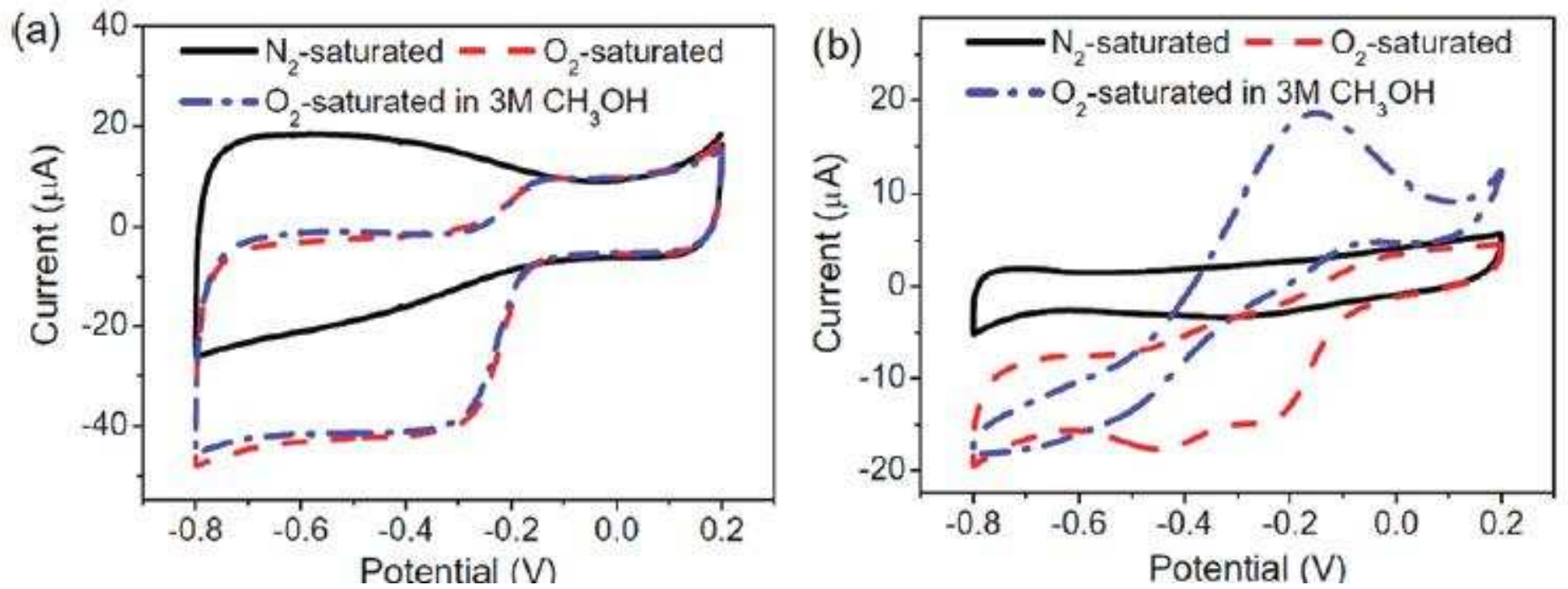

Figure 14 
(a)

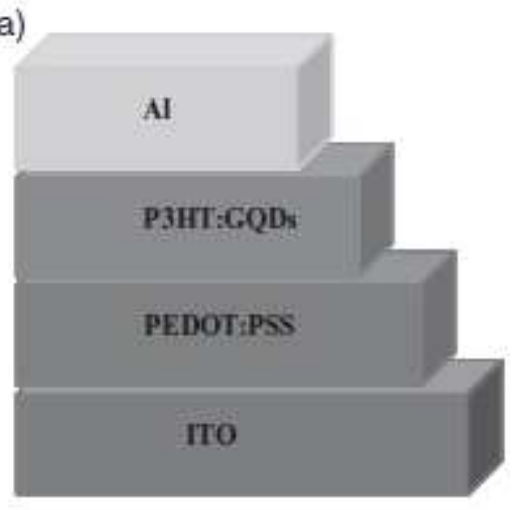

(b) то Р3нт GQDs Al

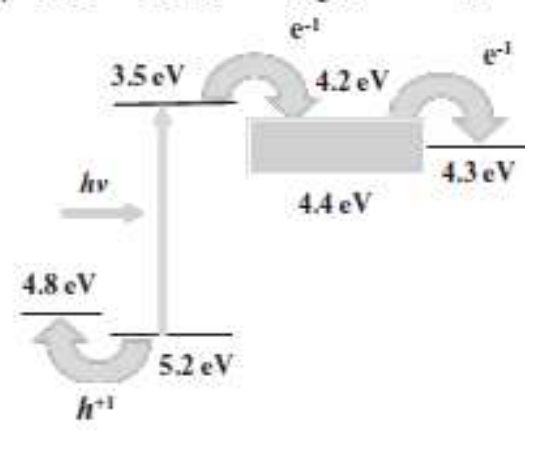

(c)

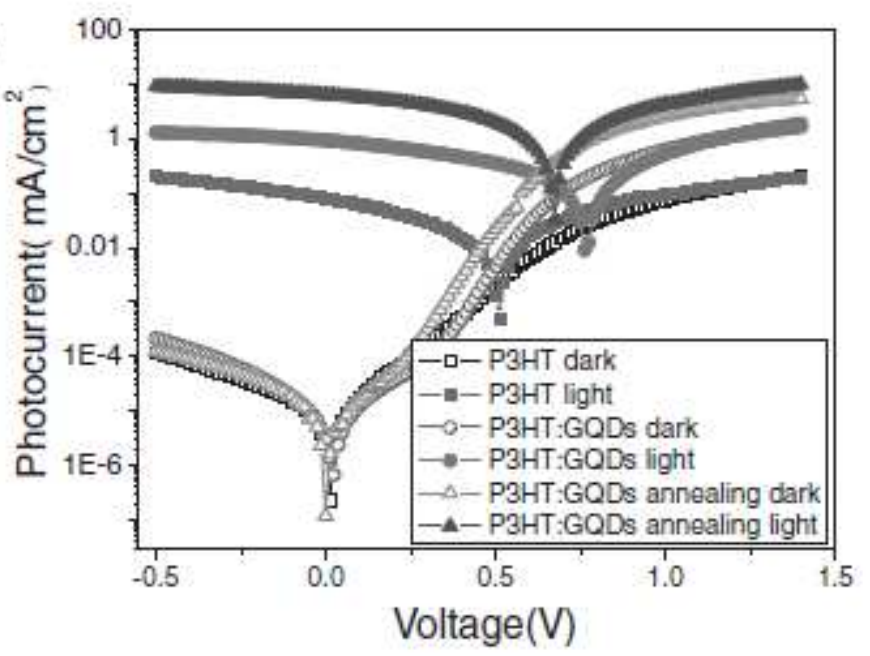

Figure 15 

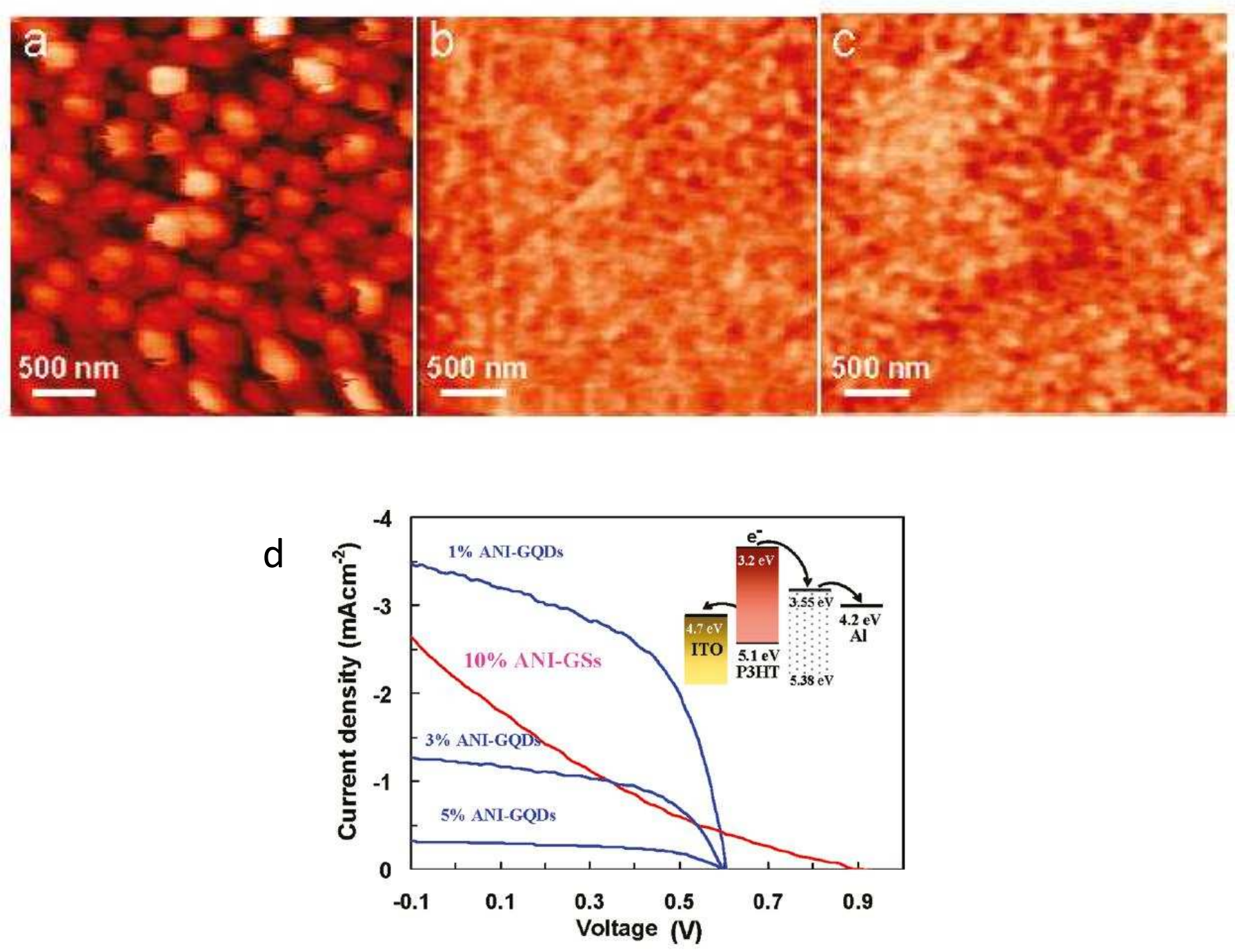

Figure 16 